\title{
A groupoid and graph-theoretical analysis of the biopyribole-palysepiole series
}

\author{
Massimo NESPOLO ${ }^{1,2^{*}}$, Akihiro UMAYAHARA ${ }^{3}$ and Jean-Guillaume EON ${ }^{4}$ \\ ${ }^{1}$ Université de Lorraine, CRM2, UMR 7036, Vandoeuvre-lès-Nancy, 54506, France. ${ }^{2} \mathrm{CNRS}$, \\ CRM2, UMR 7036, Vandoeuvre-lès-Nancy, 54506, France. ${ }^{3}$ Graduate School of Science and \\ Technology, Kumamoto University, Kumamoto 860-8555, Japan. ${ }^{4}$ Instituto de Química, \\ Universidade Federal do Rio de Janeiro, Avenida Athos da Silveira Ramos, 149 Bloco A, Cidade \\ Universitária, Rio de Janeiro 21941-909, Brazil, \\ *Corresponding author, ORCID ID: orcid.org/0000-0003-2530-5399 email \\ massimo.nespolo@univ-lorraine.fr
}

\begin{abstract}
The modular analysis of the biopyriboles-palysepioles polysomatic series recently presented by Nespolo and Bouznari (2017) is extended to take into account the local symmetry of each module and the partial operations mapping pairs of modules, to build the corresponding space groupoids. We show that the presence of pseudo-partial mirror in sepiolite and jimthompsonite leads to 40 (pseudo)-isometries, of which eight are total operations appearing in the space groups of the two structures. Chesterite can be described as a contracted twin in which a transmutation operation maps a portion of the larger module $\left(Z_{8}\right)$ onto the smaller module $\left(Z_{5}\right)$. The graphtheoretical analysis of these minerals confirms the results obtained by the application of the groupoid theory.
\end{abstract}

Key-words: biopyriboles; contracted twin; graph-theory; labelled quotient graphs; modularity; modular crystal structures; palysepioles; pseudo-symmetry; tropochemical cell-twinning; space groupoids.

\section{Introduction}

In our recent article (Nespolo and Bouznari, 2017) we have shown that the minerals forming the polysomatic series of biopyriboles (pyroxenes, micas, amphiboles, jimthompsonite, chesterite) and of palysepioles (palygorskite, sepiolite, kalifersite) can all be described in the framework of the tropochemical-cell twinning mechanism (Takéuchi, 1997) as obtained from a single prototype, the phyllosilicates. By extracting rods of various width $R_{\mathrm{n}}$, where $\mathrm{n}$ is the number of octahedra along the $\mathbf{b}$ direction, and stacking these rods through different structure-building operations, we obtain the skeleton of all the minerals in the two series, to be completed by additional components (atoms or water molecules) at the boundary between rods. We have emphasized the close structural similarity of the various structures by expressing the fractional atomic coordinates of a $Z_{n}$ module (the zero-periodic module corresponding to the portion of the $R_{\mathrm{n}}$ rod contained in a single unit-cell) of a phyllosilicate in the axial setting of the other minerals containing the same type of $Z_{n}$ module. The results are extremely close to the experimental fractional atomic coordinates of the respective minerals, even despite differences in the atomic species occupying corresponding coordination polyhedra. In order to compare the fractional atomic coordinates of the different minerals in a common axial setting, we had to choose a non-conventional space group setting for some of the structures, like $A 2 / \mathrm{m}$ instead of $C 2 / \mathrm{m}$ for phlogopite or $I 2 / \mathrm{m}$ instead of $C 2 / \mathrm{m}$ for tremolite. In this article, we analyse the (pseudo)-symmetry of each mineral separately, without the need to change its 
setting. We refer the reader to Nespolo and Bouznari (2017) for a general introduction to the biopyribole-palysepiole series, with an extensive literature survey that we do not repeat here for the sake of brevity.

We consider the operations mapping the various modules to build the corresponding space groupoids (Brandt, 1927) which describe their full symmetry. The procedure has been presented in our article on pyroxenes (Nespolo and Aroyo, 2016); we refer the reader to that article for details. Nevertheless, because the subject is probably less familiar to many readers, we summarize below the general guidelines.

The full symmetry of a modular structure is composed of three types of operation:

1. local operations: symmetry operations of the module, which act in the subspace spanned by the module itself;

2. partial operations: operations mapping different modules; a given partial operation is in general defined only for the pair of modules to which it applies;

3. total (global) operations: ordinary space-group operations valid in the whole space where the structure exists.

The set of local operations forms a subperiodic group (point, rod, or layer group for a 0-, 1- and 2-periodic object), called the kernel of the module. A structure composed by $n$ identical modules is characterized by $n$ kernels, isomorphic to each other, differing for their orientation and/or position in space. In the following, we will denote the modules by a capital letter and the corresponding kernel will bear that letter as a subscript: $K_{X}$ is the kernel of module $X$, where $X=A, B, C \ldots$ and so on.

A partial operation mapping two different modules will be noted as $h_{i}$, where $i$ is a sequential number. The target module is constant, let us say A, whereas the source module varies with i. For example, $\mathrm{h}_{1}$ maps $\mathrm{B}$ to $\mathrm{A}, \mathrm{h}_{2}$ maps $\mathrm{C}$ to $\mathrm{A}$, and so on $\left(\mathrm{h}_{0}\right.$ is simply the identity, i.e. a local operation of A). The product of two partial operations is not, in general, a mapping of two existing modules, consistent with the fact that the partial operations of a groupoid do not obey the closure property of a group. On the other hand, the products $h_{i}^{-1} h_{j}$ and $h_{j}{ }^{-1} h_{i}$ do map existing modules. For example, $h_{1}{ }^{-1}$ maps $A$ to $B$ and $h_{2}{ }^{-1}$ maps $A$ to $C$, so that $h_{1}{ }^{-1} h_{2}$ maps $C$ to $B$ via $A(C \rightarrow A \rightarrow B)$ and $h_{2}{ }^{-1} h_{1}$ maps $B$ to $\mathrm{C}$ via $\mathrm{A}(\mathrm{B} \rightarrow \mathrm{A} \rightarrow \mathrm{C})$.

The product of a local operation and a partial operation is again a partial operation that maps the same pair of modules for a different but equivalent configuration of the target module A. For example, the product $\mathrm{K}_{\mathrm{A}} \mathrm{h}_{1}$ is the set of all partial operations mappings $\mathrm{B}$ to A. By making this result general, the product $\mathrm{K}_{\mathrm{A}} \mathrm{h}_{\mathrm{i}}$, where $\mathrm{i}=[1, \mathrm{n}-1]$, $\mathrm{n}$ being the number of modules, is the set of all partial operations mapping any module $\mathrm{X} \neq \mathrm{A}$ to $\mathrm{A}$; it does not form a group but a set called the hull of $\mathrm{A}$, $\mathrm{H}_{\mathrm{A}}$. By adjoining the kernel and the hull of a module A one obtains what Loewy (1927) has called Mischgruppe of that module, a term which has been translated as hybrid group (Sadanaga, personal communication) or compound group (Brown, 1987), although it is not a group but a set of operations:

$$
\mathrm{M}_{\mathrm{A}}=\mathrm{K}_{\mathrm{A}} \cup \mathrm{H}_{\mathrm{A}}=\mathrm{K}_{\mathrm{A}} \cup_{\mathrm{i}} \mathrm{K}_{\mathrm{A}} \mathrm{h}_{\mathrm{i}}
$$

We have seen that $h_{2}^{-1} h_{1}$ is a partial operation mapping $B$ to $C$ via $A$ and that $K_{A} h_{1}$ is the set of all the partial operations mapping B to A. Then, $\mathrm{h}_{2}{ }^{-1} \mathrm{~K}_{\mathrm{A}} \mathrm{h}_{1}$ is the set of all the partial operations mapping $B$ to $C$ via $A$. By making this result general, $h_{j}^{-1} K_{A} h_{i}$ is the set of all the partial operations mapping two different modules via $A$. If now we take $j=i$, the set becomes $h_{i}^{-1} K_{A} h_{i}$ and contains all the 
operations mapping a module $X \neq A$ to itself via $A$. Because the modules are identical but differently oriented/located in space, $\mathrm{h}_{\mathrm{i}}^{-1} \mathrm{~K}_{\mathrm{A}} \mathrm{h}_{\mathrm{i}}$ is the set of the local operations of $\mathrm{X}$, i.e. the kernel of $X$. Indeed, $h_{i}{ }^{-1} K_{A} h_{i}$ is the conjugation of $K_{A}$ via $h_{i}$, and conjugation is a similarity transformation.

Finally, by applying the partial operation $h_{j}^{-1}(A \rightarrow X)$ to the hybrid group of $A$, we obtain:

$$
h_{j}^{-1} M_{A}=h_{j}^{-1} K_{A} \cup h_{j}^{-1} H_{A}=h_{j}^{-1} K_{A} \cup_{i} h_{j}^{-1} K_{A} h_{i}=h_{j}^{-1} K_{A} h_{j} \cup_{i \neq j} h_{j}^{-1} K_{A} h_{i}=K_{X} \cup_{i \neq j} h_{j}^{-1} K_{A} h_{i}
$$

which is the set of all the local operations (i.e. the kernel) of $\mathrm{X}$ and of the partial operations mapping any module but $X$ to $X$ (i.e. the hull of $X$ ). In other words, $h_{j}^{-1} M_{A}$ is simply $M_{X}$, the hybrid group of module $\mathrm{X}$. The complete set of all the mappings obtained by making not only $\mathrm{i}$ but also $\mathrm{j}$ a running index gives the space groupoid $\mathrm{D}$ of the structure:

$$
\mathrm{D}=\cup_{\mathrm{ij}} \mathrm{h}_{\mathrm{j}}^{-1} \mathrm{~K}_{\mathrm{A}} \mathrm{h}_{\mathrm{i}}
$$

where the indices $\mathrm{i}$ and $\mathrm{j}$ run from 0 to $\mathrm{n}-1 ; \mathrm{h}_{0}$ is the identity operation. The structure of the groupoid

\begin{tabular}{|c|c|c|c|c|c|c|}
\hline $\mathrm{M}_{\mathrm{A}}=$ & $\mathrm{K}_{\mathrm{A}}$ & $\cup \mathrm{K}_{\mathrm{A}} \mathrm{h}_{1}$ & $\cup \mathrm{K}_{\mathrm{A}} \mathrm{h}_{\mathrm{i} 2}$ & $\cup^{\cdots} \cup \mathrm{K}_{\mathrm{A}} \mathrm{h}_{\mathrm{p}}$ & $\cup^{\cdots}$ & $\cup \mathrm{K}_{\mathrm{A}} \mathrm{h}_{\mathrm{n}}$ \\
\hline $\mathrm{M}_{\mathrm{B}}=$ & $\mathrm{h}_{1}^{-1} \mathrm{~K}_{\mathrm{A}}$ & $\mathrm{K}_{\mathrm{B}}$ & $\cup \mathrm{h}_{1}^{-1} \mathrm{~K}_{\mathrm{A}} \mathrm{h}_{2}$ & $\cup \mathrm{h}_{1}^{-1} \mathrm{~K}_{\mathrm{A}} \mathrm{h}_{\mathrm{p}}$ & $\cup^{\cdots}$ & $\cup \mathrm{h}_{1}^{-1} \mathrm{~K}_{\mathrm{A}} \mathrm{h}_{\mathrm{n}}$ \\
\hline $\mathrm{M}_{\mathrm{C}}=$ & $\mathrm{h}_{2}^{-1} \mathrm{~K}_{\mathrm{A}}$ & $\cup \mathrm{h}_{2}{ }^{-1} \mathrm{~K}_{\mathrm{A}} \mathrm{h}_{1}$ & $\mathrm{~K}_{\mathrm{C}}$ & $\cup \mathrm{h}_{2}^{-1} \mathrm{~K}_{\mathrm{A}} \mathrm{h}_{\mathrm{p}}$ & $\cup \cdots$ & $\cup \mathrm{h}_{2}{ }^{-1} \mathrm{~K}_{\mathrm{A}} \mathrm{h}_{\mathrm{n}}$ \\
\hline$\cdots$ & $\cdots$ & $\begin{array}{ll}\ldots & \ldots\end{array}$ & $\ldots$ & $\begin{array}{llll}\ldots & \ldots & \cdots & \cdots\end{array}$ & $\ldots \quad \ldots$ & $\begin{array}{ll}\ldots & \ldots\end{array}$ \\
\hline $\mathrm{M}_{\mathrm{z}}=$ & $\mathrm{h}_{\mathrm{n}}^{-1} \mathrm{~K}_{\mathrm{A}}$ & $\cup \mathrm{h}_{\mathrm{n}}^{-1} \mathrm{~K}_{\mathrm{A}} \mathrm{h}_{1}$ & $\cup \mathrm{h}_{\mathrm{n}}^{-1} \mathrm{~K}_{\mathrm{A}} \mathrm{h}_{2}$ & $\cup \mathrm{h}_{\mathrm{n}}^{-1} \mathrm{~K}_{\mathrm{A}} \mathrm{h}_{\mathrm{p}}$ & $\cup^{\cdots}$ & $\cup \mathrm{K}_{\mathrm{Z}}$ \\
\hline
\end{tabular}
can be shown in a tabular form:

The operations in each hybrid group map the various modules to one and the same target module. A subset of these operations may however occur in more than one hybrid group, i.e. map some of the modules to more than one target module. If this occurs for all target modules, than the corresponding operations become total (global) operations of the structure. This is true at least for the identity operation of each module, which becomes the only identity operation of the whole structure. For a structure composed by $\mathrm{n}$ identical modules, the groupoid is composed by $\mathrm{n}$ hybrid groups; each hybrid group is composed by one kernel and n-1 hulls; the groupoid is then composed by $\mathrm{n}^{2}$ blocks. If the kernel is composed by $\mathrm{m}$ local operations, than the groupoid contains $\mathrm{mn}^{2}$ operations, in general not all distinct, distributed in $\mathrm{n}^{2}$ blocks.

In the following, we present the groupoid analysis of the minerals in the biopyribole-palysepiole series $^{1}$ and show how to obtain their space-group operations from the set of local and partial operations. Partial operations may be pseudo-isometries, i.e. operations approximately mapping two modules: we do consider these operations in the groupoid structure, because of the important role of pseudo-symmetry in structural science (phase transitions, twinning, etc.). This corresponds to implicitly perform a small idealization of the structure, under which the pseudo-partial operation can be treated as truly partial operations.

The case of pyroxenes has already been analysed by Nespolo and Aroyo (2016) and reinterpreted in terms of labelled quotient graphs by Eon (2017): we refer the reader to that article for details. The other minerals of the biopyriboles-palysepioles series are analysed below. Before approaching that

1 The structural data used here are the same used also in Nespolo and Bouznari (2017); the references are quoted in that article. 
analysis, however, we need to review briefly some fundamental crystallographic definitions and symbols the reader may not necessarily be familiar with.

\section{Elements, operations and symbols}

A symmetry operation is an isometry (or congruence), i.e. a distance-preserving mapping (or transformation) that relates equivalent orientations/positions of an object. Symmetry operations from which the screw or glide component - if any - is removed leave invariant a subspace: a point, a line or a plane. This subspace is called the geometric element of the symmetry operation. In a space group, an infinite number of symmetry operations share the same line or plane; they differ for a lattice translation. The set of symmetry operations sharing the same geometric element is called the element set. Among the operations of the element set, the one characterised by the shortest positive screw (for rotations) or glide (for reflections) component is called the defining operation, because it is used to define the symmetry element (de Wolff et al. 1989, 1992; Flack et al. 2000). In the following analysis, we are going to obtain some operations of the element set beyond the defining operation. It is therefore important that the reader understands the concept and the corresponding symbols used.

The Hermann-Mauguin symbol of glide reflections and screw rotations are $g(p, q, r) x, y, z$ and $\mathrm{n}(p, q, r) x, y, z$ respectively, where $g$ stands for glide, $\mathrm{n}$ is the order of the rotation $(2 \pi / \mathrm{n}), p, q, r$ are the components of the glide or screw vector and $x, y, z$ are the coordinates of the geometric element. In case of (glide) reflections, special symbols are used for both the symmetry operation and the symmetry elements when $p, q, r$ take values smaller than unity: $g(0,0,0)=m ; g(1 / 2,0,0)=a ; g(0,1 / 2,0)$ $=b ; g(0,0,1 / 2)=c$; when $p, q, r$ correspond to a half-diagonal or a quarter-diagonal, special symbols $n$ and $d$ are used respectively ${ }^{2}$. The element set is composed by infinite number of (glide) reflections, whose glide component differ by a lattice translation; the one with the shortest positive (possibly zero) translation is the defining operation of the symmetry element. For example, an $a$-glide plane has as element set the operations $g( \pm 1 / 2,0,0), g( \pm 1 / 2, \pm 1,0), g( \pm 1 / 2,0, \pm 1), g( \pm 1 / 2, \pm 1, \pm 1), g( \pm 3 / 2,0,0)$, $g( \pm 3 / 2, \pm 1,0)$ and so on; of these, $g(1 / 2,0,0)=a$ is the defining operation, which gives the name and the symbol to the symmetry element.

For screw rotations, a special symbol is normally used only for symmetry elements. If $p$ is the screw component (then $q$ and $r$ are related to the location of the geometric element with respect to the origin), the defining operation is the one with the largest $n$ and the smallest positive $p(0 \leq p<$ $\mathrm{n})$; the symmetry element is then indicated as $\mathrm{n}_{\mathrm{p}}{ }^{3}$. For example, among the operations $\mathrm{n}(p, 0,0)$ sharing the line $x, 0,1 / 4$, there are $\mathrm{n}$ possible operations, corresponding to values of $\mathrm{p}$ restricted from 0 to $\mathrm{n}-1$; if $p=0$, then the defining operation is a pure rotation and the symmetry element is a rotation axis, although it is shared also by an infinite number of screw rotations $n(n, 0,0), n(2 n, 0,0) n(3 n, 0,0)$ and so on. If $p>0$, then the defining operation is a screw rotation, there is no pure rotation in the element set and the symmetry element is therefore called a screw axis. For the sake of brevity, when $p$ takes an integer value, the same shortened notation used for symmetry elements can be used also for operations (Nespolo, 2017). For example, $2_{2} x, 0,1 / 4$ and $2_{3} x, 0,1 / 4$ is a handy notation for $2(1,0,0)$ $x, 0,1 / 4$ and $2(3 / 2,0,0) x, 0,1 / 4$. This notation may look unusual, but symbols like 2 with $\mathrm{r}$ not restricted

2 The values of $p, q, r$ that correspond to a half- or quarter-diagonal depend on how the geometric element is oriented with respect to the basis vectors.

3 We need to specify "the largest n" because rotations of different order may share the same geometric element. For example, about the same line (geometric element) we may have operations $4,4^{2}=2,4^{3}$ and $4^{4}=1$. The largest $n$, in this example $n=4$, corresponds to the defining operation and the symmetry element is a fourfold rotation axis. 
to 1 , are extensively used in the OD theory (Dornberger-Schiff and Grell-Niemann, 1961). In case of partial operations, $p$ is not limited to integer values. For example, a two-fold rotation followed by a $1 / 4$ translation is not a space-group operation but is a possible partial operation, noted $2(1 / 4,0,0)$ $x, 0,1 / 4$, or synthetically $2 \frac{1}{2} x, 0,1 / 4$. Some of the partial operations we are going to obtain in the following analysis belong to the element set of a symmetry element but are not the defining operations: the synthetic notation $2_{r}$ is used in these cases. When $p$ takes irrational values, however, the shortened notation is no longer advantageous and will not be used.

\section{Topological analysis based on the Labelled Quotient Graph (LQG)}

The so-called vector method uses graph-theoretical techniques to represent and analyse the combinatorial topology of crystal structures. The method has been extensively described in two recent papers of one of the authors (Eon, 2016; 2017) but goes back to the work of Chung et al. (1984). As a rough guide to the reader, this section summarizes the main features of the method needed to follow our interpretation of modular structures. The case of diopside, with the characterization of the $R_{2}$ rod, will be examined as an illustration of the abstract concepts. In the next sections we will focus on the description of phlogopite, palygorskite, sepiolite and jimthompsonite using the $R_{2}$ rod. Only the main components of each structure are taken into account.

A crystal structure can be seen as a net of chemical bonds that is commonly summarized in the form of a graph, where atoms are symbolized by a vertex (or a point) and a bond between two atoms is symbolized by an edge (or a line) joining the corresponding vertices. This graph is called the bond graph of the structure. The quotient graph is essentially a restriction of the bond graph of the structure to the unit cell, but it also encodes the bonds to neighbouring unit cells. Whereas the conventional unit cell is best suited to describe the symmetry of the structure, a primitive unit cell is preferable (but not mandatory) to obtain a quotient graph, because the conventional unit cell would provide an extended version of it. Quotient graphs built from a primitive unit cell represent the network of interatomic bonds of the set of atoms obtained by applying to each atom in the unit cell the full set of translations of the space group, i.e. the $P 1$ translationengleiche subgroup ( $t$-subgroup) of the space group G. Any atom in the asymmetric unit generates, under the action of G, a crystallographic orbit (Engel et al., 1984). When the $P 1 t$-subgroup is considered instead of the full group G, this orbit is split into a set of suborbits, which in graph theory are called point-lattices (Chung et al., 1984). The quotient graph is the graph of chemical bonds in the $P 1 t$-subgroup expressed in the primitive unit cell. It provides the necessary information about the existence of bonds between atoms belonging to the different point-lattices but does not specify which atoms in these point-lattices are bonded. This information is retrieved from the labelled quotient graph (LQG), which includes also the information about translationally equivalent atoms,

Given a periodic structure and a reference unit cell, the respective labelled quotient graph can be constructed in two steps. Initially, every atom in the unit cell is represented by an isolated vertex (a point) $\mathrm{V}_{\mathrm{i}}(\mathrm{i}=1, n)$ and all bonds between atoms in the unit cell are represented by an edge (a line segment or an arc) joining the representative vertices, thus giving a finite graph $G$ associated to the combinatorial topology of the unit cell. In a 3-dimensional framework, some atoms in the unit cell must obviously be linked to atoms in neighbouring cells. Suppose that atom $\mathrm{V}_{\mathrm{i}}$ in the reference cell, is bonded to atom $V_{j}^{\prime}$ in a neighbouring unit cell such that the translation $\{1 \mid p q r\}$ (in the Seitz notation: Glazer et al., 2014) maps atom $V_{j}$ in the reference unit cell to this atom $V^{\prime}{ }_{j}$. Then we add an edge $\mathrm{V}_{\mathrm{i}} \mathrm{V}_{\mathrm{j}}$ to our graph $\mathrm{G}$; this edge is oriented from $\mathrm{V}_{\mathrm{i}}$ to $\mathrm{V}_{\mathrm{j}}$ and carries the triple label pqr that, in topological graph theory, is called the voltage on the edge $\mathrm{V}_{\mathrm{i}} \mathrm{V}_{\mathrm{j}}$. If the orientation of the edge is 
inverted to $\mathrm{V}_{\mathrm{j}} \mathrm{V}_{\mathrm{i}}$ the voltage must be changed to the opposite triple $\overline{p q r}$, in keeping with the previous definition. The final result is the labelled quotient graph G: note that different choices of unit cell and basis vectors for the translation group generally provide different - but equivalent - labelled quotient graphs. The keys for labelled quotient graphs analysed in this work were extracted from the CIF files by using the program package TOPOS (Blatov et al., 2014). The LQG of diopside is shown in Figure 1 $(a)$ with relation to a primitive unit cell. For the sake of clarity, the different voltages have been coded as different colours with the same colour code in all shown LQGs.

The sum of all voltages along a cycle of the LQG, where all edges have been given the same orientation as the cycle, is called the net voltage over the cycle. Any cycle of the LQG can be interpreted as the projection of a path between two translationally equivalent atoms in the crystal structure; the respective net voltage provides the vector of the translation mapping the two extremities of this path. For instance, the two $\mathrm{Si}_{2} \mathrm{O}_{2}$ 4-cycles at the inferior and superior part of the LQG of diopside in Figure 1 $(a)$ have net voltage 001; these cycles are the projections on the LQG of the two infinite $\mathrm{SiO}$ tetrahedral chains of diopside running along [001].

Building blocks in complex crystal structures also have their counterpart in the respective labelled quotient graph. They should appear as labelled subgraphs of the LQG with rank equal to the periodicity of the building block, where the rank of a labelled subgraph is defined as the rank (the dimension) of the subgroup of $Z^{3}$ (the additive group of triples of integers) generated by the net voltages over all cycles in the subgraph. The edges linking two vertices that belong to different representative subgraphs indicate the linkage type between building blocks. A simplified LQG can be constructed by taking the representative subgraphs as new vertices, thus collapsing every edge inside these subgraphs. In other words, the whole blocks are considered as vertices of the structure instead of their constitutive atoms; the topology associated to block linkage is represented by the simplified LQG. Evidencing building blocks generally requires some manipulations of the LQG such as vertex duplication and edge relabelling. Figure 1 $(b)$ shows a modified diopside's LQG that puts into evidence the $R_{2}$ rod (the I-beam of pyroxenes). Vertices with the same colour contour belong to, and make the connection between, two adjacent, translationally equivalent rods. From this LQG, one can form i) the LQG drawn in Figure 2(a), representing the topology of an isolated $R_{2}$ rod, and ii) the simplified LQG drawn in Figure 2(b), evidencing the linking mode between the rods in the diopside structure. Note first that the LQG of the rod has rank 1: the rod is one-periodic along [001]. The simplified LQG has rank 2 and shows that the linkage of $R_{2}$ rods corresponds to a sql (square lattice) topology in the (001) plane. Double edges indicate a double linkage between pairs of rods in each direction.

Symmetry operations in the crystal structure are associated to automorphisms of the quotient graph (i.e. permutations of vertices and edges which are consistent with incidence relationships). Such automorphisms must also be consistent with net voltages over cycles, i.e. any closed walk with zero net voltage must map a closed walk with zero net voltage. Conversely, any automorphism of the LQG with such properties represents a possible symmetry of the crystal structure. If it does not correspond to an actual symmetry operation, it can be interpreted as a pseudo-symmetry. Dashed blue and purple lines in Figure $1(b)$ act as reflection lines for the drawing: they determine two mirror-like automorphisms (symmetry operations) of the LQG of the $R_{2}$ rod. These automorphisms will be called exchanges across the line in order to avoid any anticipation concerning the nature of the derived symmetry operation of the crystal structure. A detailed analysis of the cycles (and net voltage over cycles) permutation shows that they correspond to the 2-fold rotation (associated to the exchange across the blue line) and the $c$ glide reflection (associated to the exchange across the purple line). These observations lead, as it could be expected, to the known 
246

\section{Prototype structure: phyllosilicates}

The prototype structure of phyllosilicates is obtained by stacking a layer $L$ parallel to itself along the $\mathbf{c}$ direction. The layer itself is obtained by repeating a rod $R_{\mathrm{n}}$ along the $\mathbf{b}$ direction and can be interpreted as $L=R_{\infty}$ (Nespolo and Bouznari, 2017). The operations building $L$ from $R_{\mathrm{n}}$ depend on the choice of the rod width $\mathrm{n}$. One can choose a $\mathrm{R}_{3}$ rod and an $a$-glide at $x, 1 / 4, z$. or a $R_{4}$ rod and a $C$ $(\mathbf{a} / 2+\mathbf{b} / 2)$ translation. The result is obviously the same. We illustrate the procedure in detail for the case of $\mathrm{R}_{3}$.

Figure 3 shows the three $\mathrm{Z}_{3}$ modules $\mathrm{A}, \mathrm{B}$ and $\mathrm{C}$, which are the zero-periodic counterpart of the $R_{3}$ rods, as well the partial operations $\mathrm{h}_{1}$ mapping $\mathrm{B}$ to $\mathrm{A}$, i.e. an $a$-glide at $x, 1 / 4, z$, and $\mathrm{h}_{2}$ mapping C to $A$, i.e. $\mathrm{t}(0,0,1)$ translation. The product $\mathrm{h}_{1}{ }^{-1} \mathrm{~h}_{2}$ maps $\mathrm{C}$ to $\mathrm{B}$ via $\mathrm{A}$ and is a glide reflection $g(\overline{1} / 2,0,1)$ about the plane at $x, 1 / 4, z$. This is one of the infinite operations building the element set that share the same geometric element; the corresponding defining operation is $g(1 / 2,0,0)=a$, i.e. the operation mapping $\mathrm{B}$ to $\mathrm{A}$. The inverse operation $\mathrm{h}_{2}{ }^{-1} \mathrm{~h}_{1}$ is $g(1 / 2,0,1)$ and maps $\mathrm{B}$ to $\mathrm{C}$ via $\mathrm{A}$.

The whole set of operations mapping A,B,C $\leftrightarrow$ A,B,C in all possible combinations contains 4 (operations of the kernel) $\times 3^{2}=36$ operations. These are the operations of the groupoid but are not all distinct. The rod symmetry of the $R_{3} \operatorname{rod}$ is $h_{a} 12 / m 1$ (symbols of sub-periodic groups from Kopský and Litvin, 2010), and is the kernel of the module. The groupoid structure is then immediately obtained.

$$
\begin{array}{lll}
h_{a} 12 / m 1 & \cup h_{a} 12 / m 1 a_{x, 1 / 4, z} & \cup h_{a} 12 / m 1 \mathrm{t}(0,0,1) \\
a_{x, 1 / 4, z}^{-1} h_{a} 12 / m 1 & \cup a^{-1}{ }_{x, 1 / 4, z} h_{a} 12 / m 1 a_{x, 1 / 4, z} & \cup a^{-1}{ }_{x, 1 / 4, z} / h_{a} 12 / m 1 \mathrm{t}(0,0,1) \\
\mathrm{t}^{-1}(0,0,1) h_{a} 12 / m 1 & \cup \mathrm{t}^{-1}(0,0,1) h_{a} 12 / m 1 a x, 1 / 4, z & \cup \mathrm{t}^{-1}(0,0,1) h_{a} 12 / m 1 \mathrm{t}(0,0,1)
\end{array}
$$

If in the top-left block (kernel of module A) we write out explicitly the symmetry operations of the kernel with translational component smaller than a full lattice translation, i.e. the defining operations of the symmetry elements plus the identity, the result is the following one.

$$
\begin{aligned}
& \mathrm{M}_{\mathrm{A}} 1,21 / 2, y, 1 / 2 ; \overline{1} 1 / 2,1 / 2,1 / 2 ; m x, 1 / 2, z \quad \cup a x, 1 / 4, z ; \overline{1}_{11 / 4,1 / 4,1 / 2 ; 2}, 1 / 4, y, 1 / 2 ; \\
& \mathrm{t}(1 / 2,1 / 2,0) \\
& \mathrm{M}_{\mathrm{B}} \quad a^{-1} x, 1 / 4, z ; \overline{1} 1 / 4,1 / 4,1 / 2 ; 22_{1}^{1 / 4}, y, 1 / 2 ; \quad \cup 1 ; 20, y, 1 / 2 ; \overline{1} 0,0,1 / 2 ; m x, 0, z \\
& \mathrm{t}\left(\overline{1 / 2}, \frac{1}{1 / 2}, 0\right) \\
& \mathrm{M}_{\mathrm{C}} \mathrm{t}(0,0, \overline{1}) ; 21 / 2, y, 0 ; \overline{1} 1 / 2,1 / 2,0 \text {; } \\
& g(0,0,1) x, 1 / 2, z \\
& \underset{\mathrm{t}(1 / 2,1 / 2, \overline{1})}{\operatorname{g(1/2,0,\overline {1})} x, 1 / 4, z ; \overline{1} 1 / 4,1 / 4,0 ; 2} 2_{1}^{1 / 4, y, 0}
\end{aligned}
$$

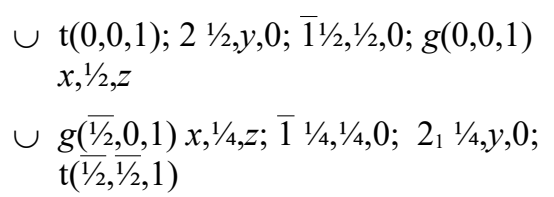

$$
\begin{aligned}
& \cup 1 ; 21 / 2, y, \overline{1} / 2 ; \overline{1} 1 \frac{1}{2}, 1 / 2, \overline{1} / 2 ; m x, 1 / 2, z
\end{aligned}
$$

If we consider the kernel and the first hull of $\mathrm{M}_{\mathrm{A}}$ and $\mathrm{M}_{\mathrm{B}}$, i.e. the $2 \times 2$ block at the top-left of the groupoid, we obtain the layer group of the $c 2 / m 11$, No. 18 in volume E of the International Tables for Crystallography (Kopský and Litvin, 2010), or C12/m(1) in the OD notation (DornbergerSchiff, 1959). Indeed, a full lattice translation along a is contained in the rod symmetry and a full 
lattice translation about $\mathbf{b}$ is obtained by applying twice the partial operation $2,1 / 4, y, 1 / 2$. The operations that look different in the two hybrid groups are simply related by a unit translation in plane of the layer. For example, $2_{0, y, \frac{1}{2}}$ is obtained by combining $2_{\frac{1}{2}, y, 1 / 2}$ and a unit translation along a, $\overline{1}_{0,0,1 / 2}$ from $\overline{1}_{1 / 2,1 / 2,1 / 2}$ and a unit translation along $\mathbf{a}+\mathbf{b}, m_{x, 0, z}$ from $m_{x, 1 / 2, z}$ and a unit translation along $\mathbf{b}$. The operation $a_{x, 1 / 4, z}^{-1}$, in $\mathrm{h}_{1}^{-1} \mathrm{~K}_{\mathrm{A}}$ is $g(\overline{1} / 2,0,0)$. The $a$-glide planes at $x, 3 / 4, z$ and at $x, \overline{1 / 4}, z$ do not appear explicitly in this analysis because they are at the boundary of the pair of modules BA but are generated when combining the $a$-glide reflection at $x, 1 / 4, z$ with a full translation along $\pm \mathbf{b}$. These are therefore global operations for the layer.

The operations in the second hull of the first and second hybrid groups, as well as those in the third hybrid group $\left(\mathrm{M}_{\mathrm{C}}\right)$, map different layers along the stacking direction $\mathbf{c}$, by a full translation, a glide reflection with a full translation (noted $g$ ), an inversion at $z=0$ or a screw rotation about an axis at $z=0$. They are again global operations, because they, or their translational equivalent, occur in all hybrid groups. In fact:

- $\mathrm{t}(0,0,1)$ in $\mathrm{M}_{\mathrm{A}}$ is equivalent to $\mathrm{t}(\overline{1 / 2}, \overline{1} / 2,1)$ in $\mathrm{M}_{\mathrm{B}}$ through the $C$ translation of the layer group, and to $\mathrm{t}(0,0, \overline{1})$ of $\mathrm{M}_{\mathrm{C}}$ by $2 \mathrm{c}$ translation;

- $\quad 2 \frac{1}{2}, y, 0$ occurs in both $\mathrm{M}_{\mathrm{A}}$ and $\mathrm{M}_{\mathrm{C}}$ is equivalent to $20, y, 1 / 2$, in $\mathrm{M}_{\mathrm{B}}$ by a translation $-\mathbf{a}+\mathbf{c}$;

- $\overline{1} 1 / 2,1 / 2,0$ occurs in both $\mathrm{M}_{\mathrm{A}}$ and $\mathrm{M}_{\mathrm{C}}$ is equivalent to $1 / 2,0,1 / 2$ in $\mathrm{M}_{\mathrm{B}}$ by a translation $\mathbf{a}+\mathbf{b}-\mathbf{c}$;

- $g(0,0,1) x, 1 / 2, z$ in $\mathrm{M}_{\mathrm{A}}$ is equivalent to $g(0,0, \overline{1}) x, 1 / 2, z$ in $\mathrm{M}_{\mathrm{C}}$ through the a $-2 \mathrm{c}$ translation and to $g(\overline{1 / 2}, 0,1) x, 1 / 4, z$, of $\mathrm{M}_{\mathrm{B}}$ by a translation $-\mathbf{a} / 2+\mathbf{b} / 2$, i.e. the $C$ translation of the layer group plus a $-\mathbf{a}$ translation of the rod.

These global operations, added to the layer group and the full lattice translations give as a result the $C 12 / m 1$ space group of phlogopite. Therefore, in this case the groupoid simply degenerates to a group.

Figure 4(a) displays the LQG of phlogopite for the primitive cell defined by $\mathbf{a}^{\prime}=1 / 2(\mathbf{a}-\mathbf{b}), \mathbf{b}^{\prime}=$ $1 / 2(\mathbf{a}+\mathbf{b}), \mathbf{c}^{\prime}=\mathbf{c}$. The central cation in this graph was deleted and some oxygen atoms were split to give the LQG shown in Figure 4(b); apart from the presence of $\mathrm{OH}$ groups instead of terminal oxygen vertices, the resulting LQG shows clearly that phlogopite can be built from the $R_{2}$ rod of diopside. Whereas a 3-periodic structure is obtained in diopside by linking any rod to four neighbours in two independent directions, a 2-periodic structure is formed in phlogopite by linking each rod to two neighbours along a single direction. Moreover, linkages in diopside involve a double connection of rods between the tetrahedral chain of each rod and the octahedral chain of the other. Linkages in phlogopite occur through homogeneous connections: octahedral to octahedral and tetrahedral to tetrahedral chains. After the $R_{2}$ rods have been assembled according to the LQG given in Figure $4(b)$, the structure has to be stuffed by additional cations in octahedral coordination to yield the phlogopite structure.

To be emphasized that this analysis concerns the stacking of rods to build the one-layer polytype. Phyllosilicates, and in particular micas, occur in many different polytypes and the stacking of layers again is rationalized in terms of partial operations leading to groupoids. This is however outside the scope of the present article. Interested readers can refer to a review in Nespolo and Durovič (2002).

\section{Structures built on $\boldsymbol{R}_{5}$ rods: amphiboles and palygorskite}

The $R_{5}$ rods, whose rod symmetry (kernel) is $\mu_{\mathrm{c}} 12 / \mathrm{m} 1$, occur in amphiboles and in palygorskite. The partial operation is a $C$-centring translation in both cases; the unit cell having different dimensions, the resulting structure is different, but the symmetry (type of group) is the same. The groupoid is therefore composed by two hybrid groups, each containing a kernel and a hull. 


$$
\begin{array}{ll}
h_{c} 12 / m 1 & \cup h_{c} 12 / m 1 \mathrm{t}(1 / 2,1 / 2,0) \\
\mathrm{t}^{-1}(1 / 2,1 / 2,0) \not \mu_{c} 12 / m 1 & \cup \mathrm{t}^{-1}(1 / 2,1 / 2,0) h_{c} 12 / m 1 \mathrm{t}(1 / 2,1 / 2,0)
\end{array}
$$

310

and, by specifying the operations:

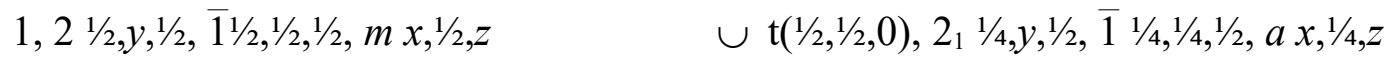

$$
\begin{aligned}
& \mathrm{t}(\overline{1} / 2, \overline{1} / 2,0), 2 \overline{1} 1 / 4, y, 1 / 2, \overline{1} 1 / 4,1 / 4,1 / 2, a^{-1} x, 1 / 4, z \cup 1,20, y, 1 / 2, \overline{1} 0,0,1 / 2, m x, 0, z
\end{aligned}
$$

As in the case of $R_{3}$, all the operations listed, or their translational equivalent, occur in both hybrid groups and are therefore global. Their set-theoretical union, results in the space-group type of the two minerals, which is $C 2 / m$ in both cases.

Figure 5 displays the LQG of palygorskite, already organized so as to put into evidence the structural role of the $R_{5}$ rod and its relation with the $R_{2}$ rod of diopside. Indeed, the left and right parts of the $R_{5}$ rod form two interlinked $R_{2}$ rods to which the central octahedral cation must be added to yield the full $R_{5}$ rod. The LQG presents two symmetry operations that can be seen as exchanges across the blue and purple dashed lines and can be associated respectively to the 2-fold rotation and the mirror reflection $m$ of palygorskite. The first reflection leaves each rod invariant while the second one exchanges the two $R_{2}$ rods, thus corresponding to an operation of the kernel of the rods and a partial operation, respectively: they are of course global symmetry operations. Hence, the $c$-glide reflection of the ideal $R_{2}$ rod (belonging to the respective kernel) is missing in the symmetry group of this structure. It may be looked at as a pseudo-symmetry of the space-groupoid of palygorskite in the extended sense that it corresponds to a symmetry operation defined by the subgraph representing the rod.

\section{Structures built on $\boldsymbol{R}_{8}$ rods: sepiolite and jimthompsonite}

As shown by Nespolo and Bouznari (2017), the $Z_{8}$ module, and thus the $R_{8}$ rod, can be almost exactly reconstructed by expanding the $Z_{5}$ module through the action of a pseudo-partial mirror, slicing the $Z_{8}$ module into a $Z_{5}$ part and $Z_{8}-Z_{5}$ part. This same relation occurs both along $+\mathbf{b}$ and along -b so that the $R_{8}$ rod can be ideally separated into three $R_{2}$ rods, below labelled as A (middle),

$\mathrm{B}$ (left) and C (right). The exact (A) and approximate (B, C) rod symmetry (kernel) is $h_{c} 12 / c 1$ and

$h_{c} 1 c 1$ respectively for sepiolite and jimthompsonite. The octahedral cations and oxygen atoms at the boundaries between the rods, i.e. approximately on the pseudo-partial mirrors, are the additional components necessary to obtain the $R_{8}$ rod from the stacking of $R_{2}$ rods. The unit cell of sepiolite contains two $\mathrm{Z}_{8}$ modules and the unit cell of jimthompsonite four; these are related by one and three partial operations respectively. These, and the corresponding $R_{8}$ rods, are labelled sequentially from 1 to 2 and from 1 to 4 respectively; the same numbering scheme is applied to the $R_{2}$ components $\mathrm{A}$, $\mathrm{B}$ and C. Concretely, the structure of the two title minerals can be obtained in two steps (Figures 6 and 7).

1. build the target $R_{8}$ rod by applying the partial operations to $R_{2} \operatorname{rod} \mathrm{A} 1$ to obtain $\mathrm{B} 1$ and $\mathrm{C} 1$ : a partial mirror reflection at $x, 0.421, z$ (sepiolite) or at $x, 0.666065, z$ (jimthompsonite) mapping A1 to $\mathrm{B} 1$ and a second partial mirror reflection at $x, 0.579, z$ (sepiolite) or at $x, 0.833935, z$ 
(jimthompsonite), mapping $\mathrm{A} 1$ to $\mathrm{C} 1$; complete the $R_{8}$ rod with the additional atoms;

2. build the structure of the two minerals by applying the mapping of different $R_{8}$ rods; this leads automatically to the mappings of $(\mathrm{Aj}, \mathrm{Bj}, \mathrm{Cj}) R_{2}$ rods in the $\mathrm{j}>1 R_{8}$ rod to the corresponding $(\mathrm{A} 1, \mathrm{~B} 1, \mathrm{C} 1) R_{2}$ rods in target $R_{8}$ rod.

For sepiolite the operation in step 2 is an $n$-glide reflection at $1 / 4, y, z$, whereas for jimthompsonite, there are three operations, namely a $b$-glide reflection at $1 / 4, y, z$, an $a$-glide reflection at $x, y, 1 / 4$, and an inversion at $1 / 2,1 / 2,1 / 2$. The two groupoids are therefore composed by $6^{2}=36$ blocks for sepiolite and $12^{2}=144$ blocks for jimtphomsonite. This means we have to derive $4 \times 36=144$ and $2 \times 144=288$ operations respectively, not all of which will turn out to be different; some of the operations obtained in this way will actually be global operations building the space group of the mineral.

The careful reader may remark a slight difference with respect to Nespolo and Bouznari (2017), concerning the position of the first pseudo-partial mirror in sepiolite (the one mapping B1 to A1), whose position was given as $x, 0.4151, z$ there whilst it is $x, 0.421, z$ here. In our previous article, the position of the pseudo-partial mirror was chosen on an octahedral cation, whereas here it is chosen so that the matrix representation of the global operations take a standard expression, with vector components equal to $0,1 / 4$ or $1 / 2$ (or integer multiples) of these. The slight difference comes evidently from the fact that these operations are $p s e u d o$-isometries.

Table 1 presents the groupoid structure of sepiolite. The 144 combinations $h_{j}{ }^{-1} K_{A} h_{i}\left(i, j=0,1,2, h_{0}\right.$ $=$ identity), result in 40 operations, listed with a sequence number in Table 2. Finally, Table 3 gives the operations in each kernel and hull by the sequential number defined in Table 2 . To be noted that some of the operations obtained in this way are not the defining operations of the corresponding symmetry element. For example, the operations No. 33, $22_{2} 1 / 4,1 / 4, z$, which is a shorthand notation for $2(0,0,1) 1 / 4,1 / 4, z$, is a screw rotation about the direction $1 / 4,1 / 4, z$ with screw component corresponding

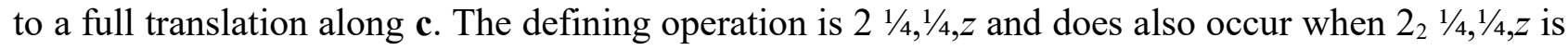
combined with a lattice translation along -c, which belongs to the rod symmetry.

The operations that occur in each hybrid group $\mathrm{M}_{\mathrm{x}}$, which are therefore global operations, are shown in bold in Table 3. As expected, these eight operations belong to Pbcn, i.e. the space-group type of sepiolite. The remaining 32 operations, i.e. $80 \%$ of the operations relating $R_{2}$ modules, are partial or local and do not appear in the space group of the mineral.

Figure 8 displays the LQG of sepiolite evidencing the structural role of two $R_{8}$ rods and their relations with the $R_{2}$ rod of diopside. Indeed, one can look at each $R_{8}$ rod as built from three interlinked $R_{2}$ rods stuffed by two octahedral cations at the third and sixth position, starting from the left or from the right of the figure. Alternatively, one can build the $R_{8} \operatorname{rod}$ by interlinking an $R_{5} \operatorname{rod}$ with an $R_{2}$ rod and stuffing it with an additional octahedral cation in the third $\left(R_{2}+R_{5}\right)$, or equivalently in the sixth position $\left(R_{5}+R_{2}\right)$. Figure 9 shows the simplified LQG of sepiolite representing the linkage of the $R_{8}$ rods. This LQG is that of the sql lattice in a body-centred cell, which indicates that the two $R_{8}$ rods are related by a translation in the (001) plane. This centring translation is associated to the permutation $\phi_{1}=(\mathrm{a}, \mathrm{d})(\mathrm{b}, \mathrm{c})$, also exchanging the two rods M1 and M2, which leaves invariant every net voltage over the cycles of the simplified LQG. However, the permutation induced by $\phi_{1}$ in the full LQG of sepiolite realizes an inversion of the [001] direction. This permutation must therefore be associated to the glide reflection $n(1 / 2,1 / 2,0)$. Partial operations between the three $R_{2}$ rods forming the $R_{8}$ rod can be deduced from those of palygorskite using the $\left(R_{2}+R_{5}\right)$ or $\left(R_{5}+R_{2}\right)$ construction. Indeed, the central $R_{2}$ rod A of $R_{8}$ belongs to the $R_{5}$ rod in both interpretations, $\left(R_{2}+R_{5}\right)$ or $\left(R_{5}+R_{2}\right)$, and so it can be obtained from any of the other two $R_{2}$ rods, $\mathrm{B}$ or $\mathrm{C}$, by a partial mirror reflection with mirror plane going through the added octahedral cations. The orientation of the mirror plane can be obtained from a complete analysis of the other two generators of the symmetry group of sepiolite using the two LQGs. It can be seen that the 
permutations $\phi_{2}=(a, c)(b, d)$ and $\phi_{3}=(a, b)(c, d)$, both fixing the two rods M1 and M2, of the simplified LQG are associated to a 2 -fold rotation $2_{010}$ and a $c$-glide reflection, respectively. This shows that the octahedral chain has its flat face parallel to the (001) plane so that the mirrors mapping the $\mathrm{A}$ rod to rods $\mathrm{B}$ and $\mathrm{C}$ are orthogonal to the 010 axis. We also note that rod $\mathrm{A}$, located at the intersection of the two possible $R_{5}$ rods is invariant by the $c$-glide reflection. This rod has thus the full $h_{c} 12 / c 1$ symmetry of the diopside $R_{2}$ rod.

Tables 4-6 present the corresponding results for jimthompsonite. The 288 combinations $h_{j}{ }^{-1} K_{A} h_{i}$ $\left(\mathrm{i}, \mathrm{j}=0,1,2, \mathrm{~h}_{0}=\mathrm{identity}\right)$, result again in 40 operations. Analogously to the case of sepiolite, an unusual symbol is used for operation No. 21, namely $2_{3} 0, y, 1 / 4$. This is a screw rotation with screw component $3 \mathbf{b} / 2$ along the $0, y, 1 / 4$ direction. It occurs in all the 12 hybrid groups and is therefore a global operation. The corresponding defining operation of the symmetry element is $2_{1} 0, y, 1 / 4$, which is obtained from $2_{3} 0, y, 1 / 4$ by combination with a -b lattice translation.

The operations that occur in each hybrid group $\mathrm{M}_{\mathrm{x}}$, which are therefore global operations, are shown in bold in Table 6. These eight operations belong to Pbca, the space-group type of jimthompsonite. As in the case of sepiolite, the remaining 32 operations (80\%) are partial or local and do not appear in the space group of the mineral.

Due to the large size of its unit cell, the LQG of jimthompsonite was divided into two figures, each evidencing the presence of two distinct rods $R_{8}$ : Figure 10 represents the two rods M1 and M2 while Figure 11 shows the two rods M3 and M4. In this structure, rods $R_{8}$ make double, heterogeneous linkages joining the octahedral chain of one rod to the tetrahedral chain of the other rod by sharing pairs of oxygen atoms. Shared pairs of oxygen atoms are indicated by identical letters in the LQG. For example, the two oxygen atoms on each side of letter "a" in rod M1 (Figure 10) should be identified with the two oxygen atoms on each side of letter "a" in rod M4 (Figure 11), each oxygen atom joining a tetrahedral chain to an octahedral one. The simplified LQG, given in Figure 12, represents the complete linkage of these rods throughout the structure; each edge in this graph carries, along with the respective voltage, the letter indicating the corresponding shared oxygen pair. This LQG can be associated to a 2-periodic topology in the (001) plane, which we identify as follows. We first observe that the graph presents an automorphism of order 4, described by the vertex permutation (M1,M2,M3,M4) and by the edge permutation $\phi=\left(a, d^{\prime}, b, c^{\prime}\right)\left(a^{\prime}, d, b^{\prime}, c\right)$, which leaves the two voltages 100 and 010 invariant and does not possess fixed vertices or edges. Hence, $\phi$ can be associated to a translation of the 2-periodic net. Because the quotient of the simplified LQG by $\phi$, has a single vertex and two edges (loops), it describes a square lattice net (sql), but with quadruple unit cell. The basis vectors of the primitive cell of this lattice are given by $1 / 4 \frac{1}{2} 0$ and $1 / 4-1 / 20$ with reference to the basis vectors of the unit cell of jimthompsonite. However, the automorphism induced by $\phi$ in the full LQG of jimthompsonite does not act consistently on the net voltages over cycles along 001, so that it cannot correspond to an isometry in Euclidean space. The net effect of this automorphism in this direction is reported by the signs $(+,-,-,+)$ carried by the vertices (M1, M2, M3, M4) of the simplified LQG: As $\phi$ maps rod M1 to rod M2, it inverts the direction [001] (+ to -), but at the same time, rod M2 is mapped to rod M3 with preservation of the direction [001] (- to -), and so on. The symmetry operation induced by $\phi$ should therefore be interpreted as an element of the space-groupoid of jimthompsonite. It appears that the operation associated to $\phi^{2}$ can be associated to the translation $\mathrm{t}(1 / 2,1,0)$ in the $(001)$ plane and systematically inverts the third direction ( + to -$)$ : this operation is thus related to the $a$-glide reflection. Reconstruction of the whole structure from an idealized $R_{8}$ rod is possible by using the information contained in the simplified LQG. First, rods are linked according to a square lattice net in the (001) 
plane. Then the symmetry groupoid operation $\phi$ is applied to get the correct inversion sequence of the rods (following direction [001]) along the main axes of the square lattice net.

\section{Chesterite as a contracted twin of jimthompsonite}

Chesterite is composed by an alternation along the $\mathbf{b}$ axis of $R_{8}$ and $R_{5}$ rods. The unit cell contains four $\mathrm{Z}_{8}$ and four $\mathrm{Z}_{5}$ modules; pairs of modules of the same type are related by an $A$ translation, i.e. $\mathbf{b} / 2+\mathbf{c} / 2$, an $a$-glide reflection about the plane $x, y, 1 / 2$, and their combination, i.e. an $n$-glide about the plane $x, y, 1 / 4$. The kernel is $\mu_{c} 1 c 1$ for $Z_{8}$ and $\mu_{c} 1 m 1$ for $Z_{5}$. The two structurebuilding operations applied to the two modules produce the space group of chesterite, of type $A 2{ }_{1} m a$; the groupoid degenerates to a group, as in the case of phlogopite, palygorskite and tremolite.

We already know that the $Z_{8}$ module can be obtained from the $Z_{5}$ module by a pseudo-partial mirror. The coexistence of these two modules makes the structure of chesterite fit Takéuchi's definition of contracted twin (Takéuchi, 1997), where the term "twin" has to be understood as "celltwin", i.e. a modular structure. The concept of contracted twin is schematically presented in Figure 13. A cell-twin is obtained by a polysynthetic repetition of a unit, let it be A, through a partial operation mapping $\mathrm{A}$ to $\mathrm{A}^{\prime}$. $\mathrm{A}$ and $\mathrm{A}^{\prime}$ are identical but differently oriented and positioned in the unit cell; the structure is composed by the sequence $\mathrm{AA}^{\prime}$. Let us indicate as $\mathrm{B}$ the unshaded portion of $\mathrm{A}$ in Figure 13. A pair of modules $B$ and $B^{\prime}$ is related by the same partial operation that related the pair $A$ and $A^{\prime}$. Because $A$ and $B$ are structurally different, there is no real operation mapping them; however, the same operation mapping $\mathrm{A}$ and $\mathrm{A}^{\prime}$, or $\mathrm{B}$ and $\mathrm{B}^{\prime}$, can be applied to the $\mathrm{B}$ part of $\mathrm{A}$ to obtain $\mathrm{B}^{\prime}$; in other words, from $\mathrm{A}$ we obtained $\mathrm{A}^{\prime}$ and contract the result by removing the part of $\mathrm{A}^{\prime}$ which is not contained in $\mathrm{B}^{\prime}$. In this way, the $\mathrm{AB}^{\prime}$ module is described as a contracted twin of $\mathrm{A}$.

If we adopt this viewpoint, the structure of chesterite (Figure 14) can be schematically idealized as in Figure 15, where $A$ and $B$ represent $Z_{8}$ and $Z_{5}$ modules respectively. The partial operations mapping pairs of modules are the following.

$$
\begin{aligned}
& \mathrm{h}_{1}: \mathrm{A} 2 \rightarrow \mathrm{A} 1 \text { and } \mathrm{B} 2 \rightarrow \mathrm{B} 1: A \text {-centring translation: } \mathrm{t}(0,1 / 2,1 / 2) \\
& \mathrm{h}_{2}: \mathrm{A} 3 \rightarrow \mathrm{A} 1 \text { and } \mathrm{B} 3 \rightarrow \mathrm{B} 1: a x y^{1 / 2} \\
& \mathrm{~h}_{3}: \mathrm{A} 4 \rightarrow \mathrm{A} 1 \text { and } \mathrm{B} 4 \rightarrow \mathrm{B} 1: n x y^{1 / 4} \\
& \mathrm{~T}_{1}: \mathrm{A} 1 \rightarrow \mathrm{B} 1: \overline{1} 1 / 4^{2} / 5^{1 / 4} \\
& \mathrm{~T}_{2}: \mathrm{A} 2 \rightarrow \mathrm{B} 1: 2_{1} 1 \frac{1}{4} / 5 z \\
& \mathrm{~T}_{3}: \mathrm{A} 3 \rightarrow \mathrm{B} 1: 1_{1}^{1} \frac{1}{2} / 5^{1 / 2} \\
& \mathrm{~T}_{4}: \mathrm{A} 4 \rightarrow \mathrm{B} 1: \overline{1}_{1}^{1 / 2} \mathbf{2}^{3 / 3 / 4}
\end{aligned}
$$

Table 7 gives the fractional atomic coordinate of the $\mathrm{B}$ right part of $\mathrm{A} 1$, the result of the application of $T_{1}$ operation, and the corresponding coordinates in $\mathrm{B} 1$, together with the differences expressed as fractional coordinates and in $\AA$. The average difference is $0.1 \AA$, which shows the very high degree of pseudo-symmetry. The same result is obtained when considering the other $\mathrm{T}$ operations.

The symbol T is used here to follow Sadanaga's definition of transmutation operation (Sadanaga, personal communication) as an operation mapping two different modules. In Sadanaga's definition, the transmutation operation is invertible (if $T_{A B}$ maps $A$ to $B$, then there exist a transmutation operation $\mathrm{T}_{\mathrm{BA}}$ that maps $\mathrm{B}$ to $\mathrm{A}$ ). We deal here with a non-invertible transmutation operation because T "shrinks" A to B by acting on the corresponding submodule of A; the hypothetical inverse operation should "expand" B to A by acting also outside the module B. The structure that 
we would obtain by considering both the partial operations $h$ and the transmutation operations $\mathrm{T}$ is therefore no longer a groupoid but a category (we remind the reader that a groupoid is an invertible category; for details see Spivak, 2014).

The same interpretation can be applied to kalifersite, for which however the quality of the available refinement is too poor to provide any quantitative analysis of the modular structure of this mineral. Kalifersite is composed of two different modules which only partly fit our definition. Nespolo and Bouznari (2017) have described the structure of kalifersite as built by a $Z_{6}$ module around the centre on the unit cell, and a $Z_{3}$ module around the origin, which however span eight and four tetrahedra respectively, instead of six and two as in the definition of the $Z_{n}$ modules. The additional tetrahedra can be seen as bridges between the $Z_{6}$ and $Z_{3}$ modules. Alternatively, the two modules could also be seen as $Z_{8}$ and $Z_{5}$ with octahedral cations removed from the two boundaries of the modules. By using this description, however, the composition of the two modules in the structure of kalifersite requires an overlap of the tetrahedra on the boundaries, which would break the general scheme common to all the other minerals of the two polysomatic series

\section{Discussion}

A non-molecular crystal structure can be decomposed in elementary building blocks of variable size. The smallest and universally known block is the coordination polyhedron, which is however not always uniquely defined (Hoppe, 1970). Bigger and more complex building blocks occur in modular structures (Nespolo et al., 2004), which are built by stacking and juxtaposing one (monoarchetypal structures) or more (polyarchetypal structures) kinds of 0-, 1- or 2-period blocks (bricks, rods, layers) and give rise to large variety of complex structures (Ferraris et al, 2008; Krivovichev, 2017). A general approach to modular structures should not only point out salient common structural features of apparently highly heterogeneous structures, as in the case of the two series of minerals we have analysed, but also display predictive power on the possible stacking modes, occurrence probability of stacking fault, diffraction features. Such a general result has been obtained in the case of OD structures (Dornberger-Schiff and Grell-Niemann, 1961), i.e. monoarchetypal modular structures built by the stacking of 2-periodic building blocks (layers), but is far from having reached its final goal in the most general case, despite some general results already present in the literature (see, e.g. Sadanaga and Ohsumi, 1979). We have shown that a groupoid and graph-theoretical analysis of modular structures built by 1-periodic building blocks (rods) looks promising as a possible extension and generalization. We plan to develop this approach to other types of modular structures in the near future.

Acknowlegments. This article is devoted to Professors Giovanni Ferraris and Stefano Merlino, pioneers of the study of modularity in crystal structures and mentors of the first author, on occasion of their $80^{\text {th }}$ birthday. This research has been conducted during a short term study abroad stay (AU) at Université de Lorraine, France, funded by the Tobitate Japan Scholarship Program. JGE thanks CNPq (Conselho Nacional de Desenvolvimento Científico e Tecnológico of Brazil) for support during this work. The critical remarks by two anonymous reviewers are gratefully acknowledged.

\section{References}

Blatov, V. A., Shevchenko, A. P. and Proserpio, D. M. (2014): Applied Topological Analysis of Crystal Structures with the Program Package ToposPro. Cryst. Growth Des. 14, 3576-3586. Brandt, H. (1927): Über eine Verallgemeinerung des Gruppenbegriffes. Math. Ann., 96, 360-366. 
Brown, R. (1987): From groups to groupoids: a brief survey. Bull. London Math. Soc., 19, 113-134. Chung, S. J., Hahn, Th. and Klee, W. E. (1984): Nomenclature and generation of three-periodic nets: the vector method. Acta Crystallogr. A40, 42-50.

de Wolff, P.M., Billiet, Y., Donnay, J.D.H., Fischer, W,. Galiulin, R. B., Glazer, A. M., Hahn, Th., Senechal, M., Shoemaker, D. P., Wondratschek, H., Hahn, Th., Wilson, A. J. C. and Abrahams, S. C. (1989): Definition of symmetry elements in space groups and point groups. Report of the International Union of Crystallography Ad-Hoc Committee on the Nomenclature of Symmetry. Acta Crystallogr. A45, 494-499.

de Wolff, P.M., Billiet, Y., Donnay, J.D.H., Fischer, W., Galiulin, R. B., Glazer, A. M., Hahn, Th., Senechal, M., Shoemaker, D. P., Wondratschek, H., Wilson, A. J. C. and Abrahams, S. C. (1992): Symbols for symmetry elements and symmetry operations. Final report of the IUCr Ad-Hoc Committee on the Nomenclature of Symmetry, Acta Crystallogr. A48, 727-732.

Dornberger-Schiff, K. (1959): On the nomenclature of the 80 plane groups in three dimensions. Acta Crystallogr., 12, 173.

Dornberger-Schiff, K. and Grell-Niemann, H. (1961): On the Theory of Order-Disorder (OD) structures. Acta Crystallogr., 14, 167-177.

Engel, P., Matsumoto, T., Steinmann, G. and Wondratschek, H. (1984). The non-characteristic orbits of the space groups. Z. Kristallogr., Supplement Issue No. 1.

Eon, J.-G. (2016): Topological features in crystal structures: a quotient graph assisted analysis of underlying nets and their embeddings. Acta Crystallogr., A72, 268-293.

Eon, J.-G. (2017): Groupoids and labelled quotient graphs: a topological analysis of the modular structure in pyroxenes. Acta Crystallogr., A73, 238-245.

Ferraris G., Makovicky E. and Merlino, S. (2008): Crystallography of modular materials. IUCr/Oxford University Press, 384 pp.

Flack, H., Wondratschek, H., Hahn, Th., and Abrahams, S. C. (2000): Symmetry Elements in Space Groups and Point Groups. Addenda to two IUCr Reports on the Nomenclature of Symmetry. Acta Crystallogr. A56, 96-98.

Glazer, A.M., Aroyo, M.I.. Authier, A. (2014), Seitz symbols for crystallographic symmetry operations. Acta Crystallogr. A70, 300-302.

Hoppe, R. (1970): The Coordination Number - an "Inorganic Chameleon". Angew. Chem. internat. Edit. . 9, 25-34.

Krivovichev, S.V. (2017). Structure description, interpretation and classification in mineralogical crystallography. Crystallogr. Rev., 23, 2-71.

Kopský V., Litvin, D. B. (2010): International Tables for Crystallography Volume E: Subperiodic groups. Wiley.

Loewy, A. (1927): Über abstrakt definierte Transmutationssysteme oder Mischgruppen. J.f. Math., 157, 239-254.

Momma, K. and Izumi, F. (2011): VESTA 3 for three-dimensional visualization of crystal, volumetric and morphology data. J. Appl. Crystallogr., 44, 1272-1276.

Nespolo, M. (2017): A practical approach to symmorphism. Cryst. Res. Techn., 52, 1600129.

Nespolo, M. and Bouznari, K. (2017): Modularity of crystal structures: a unifying model for the biopyribole-palysepiole series. Eur. J. Mineral., 27, in press

Nespolo, M. and Aroyo, M.I. (2016): The modular structure of pyroxenes. Eur. J. Mineral., 28, 189203.

Nespolo, M. and Durovič, S. (2002): Crystallographic basis of polytypism and twinning in micas. In Mottana, A., Sassi, F.P., Thompson, J.B.Jr., Guggenheim, S. (Ed.): Micas: Crystal Chemistry \& Metamorphic Petrology. Rev. Miner. Geoch., 46, 155-279. 
Nespolo, M., Ferraris, G., Ďurovič, S., Takéuchi, Y. (2004): Twins vs. modular crystal structures. $Z$. Kristallogr. 219, 773-778.

Sadanaga, R. Ohsumi, K. (1979). Basic theorems of vector symmetry in crystallography. Acta Crystallogr. A35, 115-122.

Spivak, D.I. (2014): Category Theory for the Sciences. Cambridge: MIT Press, 304 pp.

Takéuchi, Y. (1997): Tropochemical cell-twinning. A structure building mechanism in crystalline solids. Tokyo: Terra Scientific Publishing Company.

\section{FIGURE CAPTIONS}

Figure 1. (a) Labelled quotient graph of diopside with relation to a primitive unit cell and $(b)$ modification evidencing the $R_{2}$ rod. Colour code (common to all figures): octahedral cations in orange, tetrahedral cation in green and oxygen ions in red; oxygen atoms with the same colour contour should be identified. Voltages are given as coloured arrows: blue (100), red (010), black (001).

Figure 2. (a) Labelled quotient graph of the $R_{2}$ rod of diopside and $(b)$ the simplified LQG representing the rod linkages: the grey box stands for the rod.

Figure 3. The $\mathrm{Z}_{3}$ modules (the portion of the $R_{3}$ rod contained in a single unit cell) of phyllosilicates and the partial operations mapping the various modules. A is the target module; B is mapped by the $a$-glide reflection about the plane at $x, 1 / 4, z$. A lattice translation along $\mathbf{b}$ applied to the pair of $R_{3}$ rods BA produced the $R_{\infty}=L$ layer of phyllosilicates. The second operation, mapping $\mathrm{C}$ to $\mathrm{A}$, is a lattice translation along the $\mathbf{c}$ axis. The product $\mathrm{h}_{1}{ }^{-1} \mathrm{~h}_{2}=g(\overline{1 / 2}, 0,1)$ about the plane at $x, 1 / 4, z$. maps $\mathrm{C}$ to $\mathrm{B}$ via A: this is one of the operations of the element set of the $a$-glide plane. (This and the following figures of crystal structures drawn with VESTA: Momma and Izumi, 2011).

Figure 4. (a) Labelled quotient graph of phlogopite and (b) LQG obtained after deleting the central octahedral atom putting into evidence the $R_{2}$ rod of diopside. Hydrogen atoms in violet. Green arrows: 110.

Figure 5. Labelled quotient graph of palygorskite evidencing the $R_{5}$ rod. Water molecules in purple. Figure 6. The structure of sepiolite in which the two $Z_{8}$ modules are shown, one centred at the middle of the unit cell, the other centred at the origin. The $R_{8}$ rods (of which the $Z_{8}$ modules are the portion contained in a single unit cell) can be seen as composed by three $R_{2}$ rods $(\mathrm{A}, \mathrm{B}, \mathrm{C})$ related by pseudo-partial mirror reflections, completed by additional atoms on the corresponding planes (blue in the figure).

Figure 7. The structure of jimthompsonite in which the four $Z_{8}$ modules are shown. As in the case of sepiolite, the $R_{8}$ rods can be seen as composed by three $R_{2}$ rods (A,B,C) related by pseudo-partial mirror reflections, completed by additional atoms on the corresponding planes (blue in the figure).

Figure 8. Labelled quotient graph of sepiolite evidencing the two $R_{8}$ rods M1 (top) and M2 (bottom); oxygen atoms with the same colour contour should be identified.

Figure 9. Simplified LQG of sepiolite emphasizing the linkages between $R_{8}$ rods; letters on the edges indicate oxygen atoms shared by the tetrahedral chains in rods M1 and M2, as identified in Figure 8.

Figure 10. Labelled quotient graph (partial) of jimthompsonite evidencing the two $\mathrm{R}_{8}$ rods M1 (top) and M2 (bottom).

Figure 11. Labelled quotient graph (partial) of jimthompsonite evidencing the two $\mathrm{R}_{8}$ rods $\mathrm{M} 3$ (top) and M4 (bottom).

Figure 12. Simplified LQG of jimthompsonite. Signs (+ or -) over the vertices indicate the orientation of the respective rod; letters on the edges indicate the linkages between octahedral and tetrahedral chains. 
614 Figure 13. The concept of contracted twin (after Takéuchi, 1997). Left: the module A is mapped to 615 the module $\mathrm{A}^{\prime}$ by a partial operation (here represented by a mirror reflection about a vertical plane 616 drawn in red). The hatched part of the two modules can be removed to transform the result in a pair 617 of modules BB' (centre). If the hatched part is removed only on one side, we obtain a contracted 618 twin, $\mathrm{AB}^{\prime}$ (right, where the hatched part is still visible to emphasize the relation between $\mathrm{A}^{\prime}$ and $\mathrm{B}^{\prime}$ ) 619 or BA'.

620 Figure 14. The structure of chesterite, where the local $c$-glide plane of the $Z_{8}$ module is shown in 621 red and the mirror plane of the $Z_{5}$ module is shown in blue.

622 Figure 15. A schematic view of the structure of chesterite along the c axis, where the $Z_{8}$ and $Z_{5}$ 623 modules are replaced by larger A and smaller B rectangles. Partial operations map A to A and B to $624 \mathrm{~B}$, whereas transmutation operations map A to B but not B to A. Thin-line rectangle is the unit cell 625 of chesterite. 
626 Table 1. Space groupoid construction for sepiolite. $\mathrm{K}_{\mathrm{X}}$ is the kernel of the $\mathrm{X} \operatorname{rod} R_{2}(\mathrm{X}=\mathrm{A} 1, \mathrm{~B} 1$, $627 \mathrm{C} 1, \mathrm{~A} 2$, B2, C2, the partial operations are $\mathrm{h}_{1}(\mathrm{~B} 1 \rightarrow \mathrm{A} 1): m_{x, 0.42215, z} ; \mathrm{h}_{2}(\mathrm{C} 1 \rightarrow \mathrm{A} 1): m_{x, 0.5794, z} ; \mathrm{h}_{3}(\mathrm{~A} 2$ $628 \rightarrow \mathrm{A} 1): n_{1 / 4, y, z} ; \mathrm{h}_{4}(\mathrm{~B} 2 \rightarrow \mathrm{A} 1)=\mathrm{h}_{1} \mathrm{~h}_{3}=2_{1 / 4,0.17215, z} ; \mathrm{h}_{5}(\mathrm{C} 2 \rightarrow \mathrm{A} 1)=\mathrm{h}_{2} \mathrm{~h}_{3}=2_{1 x, 0.3294, z}$

\begin{tabular}{|l|l|l|l|l|l|}
\hline $\mathrm{K}_{\mathrm{A} 1}$ & $\mathrm{~K}_{\mathrm{A} 1} \mathrm{~h}_{1}: \mathrm{B} 1 \rightarrow \mathrm{A} 1$ & $\mathrm{~K}_{\mathrm{A} 1} \mathrm{~h}_{2}: \mathrm{C} 1 \rightarrow \mathrm{A} 1$ & $\mathrm{~K}_{\mathrm{A} 1} \mathrm{~h}_{3}: \mathrm{A} 2 \rightarrow \mathrm{A} 1$ & $\mathrm{~K}_{\mathrm{A} 1} \mathrm{~h}_{4}: \mathrm{B} 2 \rightarrow \mathrm{A} 1$ & $\mathrm{~K}_{\mathrm{A} 1} \mathrm{~h}_{5}: \mathrm{C} 2 \rightarrow \mathrm{A} 1$ \\
\hline $\mathrm{h}_{1}{ }^{-1} \mathrm{~K}_{\mathrm{A} 1}: \mathrm{A} 1 \rightarrow \mathrm{B} 1$ & $\mathrm{~h}_{1}{ }^{-1} \mathrm{~K}_{\mathrm{A} 1} \mathrm{~h}_{1}=\mathrm{K}_{\mathrm{B} 1}$ & $\mathrm{~h}_{1}{ }^{-1} \mathrm{~K}_{\mathrm{A} 1} \mathrm{~h}_{2}: \mathrm{C} 1 \rightarrow \mathrm{B} 1$ & $\mathrm{~h}_{1}{ }^{-1} \mathrm{~K}_{\mathrm{A} 1} \mathrm{~h}_{3}: \mathrm{A} 2 \rightarrow \mathrm{B} 1$ & $\mathrm{~h}_{1}{ }^{-1} \mathrm{~K}_{\mathrm{A} 1} \mathrm{~h}_{4}: \mathrm{B} 2 \rightarrow \mathrm{B} 1$ & $\mathrm{~h}_{1}{ }^{-1} \mathrm{~K}_{\mathrm{A} 1} \mathrm{~h}_{5}: \mathrm{C} 2 \rightarrow \mathrm{B} 1$ \\
\hline $\mathrm{h}_{2}{ }^{-1} \mathrm{~K}_{\mathrm{A} 1}: \mathrm{A} 1 \rightarrow \mathrm{C} 1$ & $\mathrm{~h}_{2}{ }^{-1} \mathrm{~K}_{\mathrm{A} 1} \mathrm{~h}_{1}: \mathrm{B} 1 \rightarrow \mathrm{C} 1$ & $\mathrm{~h}_{2}{ }^{-1} \mathrm{~K}_{\mathrm{A} 1} \mathrm{~h}_{2}=\mathrm{K}_{\mathrm{C} 1}$ & $\mathrm{~h}_{2}{ }^{-1} \mathrm{~K}_{\mathrm{A} 1} \mathrm{~h}_{3}: \mathrm{A} 2 \rightarrow \mathrm{C} 1$ & $\mathrm{~h}_{2}{ }^{-1} \mathrm{~K}_{\mathrm{A} 1} \mathrm{~h}_{4}: \mathrm{B} 2 \rightarrow \mathrm{C} 1$ & $\mathrm{~h}_{2}{ }^{-1} \mathrm{~K}_{\mathrm{A} 1} \mathrm{~h}_{5}: \mathrm{C} 2 \rightarrow \mathrm{C} 1$ \\
\hline $\mathrm{h}_{3}{ }^{-1} \mathrm{~K}_{\mathrm{A} 1}: \mathrm{A} 1 \rightarrow \mathrm{A} 2$ & $\mathrm{~h}_{3}{ }^{-1} \mathrm{~K}_{\mathrm{A} 1} \mathrm{~h}_{1}: \mathrm{B} 1 \rightarrow \mathrm{A} 2$ & $\mathrm{~h}_{3}{ }^{-1} \mathrm{~K}_{\mathrm{A} 1} \mathrm{~h}_{2}: \mathrm{C} 1 \rightarrow \mathrm{A} 2$ & $\mathrm{~h}_{3}{ }^{-1} \mathrm{~K}_{\mathrm{A} 1} \mathrm{~h}_{3}=\mathrm{K}_{\mathrm{A} 2}$ & $\mathrm{~h}_{3}{ }^{-1} \mathrm{~K}_{\mathrm{A} 1} \mathrm{~h}_{4}: \mathrm{B} 2 \rightarrow \mathrm{A} 2$ & $\mathrm{~h}_{3}{ }^{-1} \mathrm{~K}_{\mathrm{A} 1} \mathrm{~h}_{5}: \mathrm{C} 2 \rightarrow \mathrm{A} 2$ \\
\hline $\mathrm{h}_{4}{ }^{-1} \mathrm{~K}_{\mathrm{A} 1}: \mathrm{A} 1 \rightarrow \mathrm{B} 2$ & $\mathrm{~h}_{4}{ }^{-1} \mathrm{~K}_{\mathrm{A} 1} \mathrm{~h}_{1}: \mathrm{B} 1 \rightarrow \mathrm{B} 2$ & $\mathrm{~h}_{4}{ }^{-1} \mathrm{~K}_{\mathrm{A} 1} \mathrm{~h}_{2}: \mathrm{C} 1 \rightarrow \mathrm{B} 2$ & $\mathrm{~h}_{4}{ }^{-1} \mathrm{~K}_{\mathrm{A} 1} \mathrm{~h}_{3}: \mathrm{A} 2 \rightarrow \mathrm{B} 2$ & $\mathrm{~h}_{4}{ }^{-1} \mathrm{~K}_{\mathrm{A} 1} \mathrm{~h}_{4}=\mathrm{K}_{\mathrm{B} 2}$ & $\mathrm{~h}_{4}{ }^{-1} \mathrm{~K}_{\mathrm{A} 1} \mathrm{~h}_{5}: \mathrm{C} 2 \rightarrow \mathrm{B} 2$ \\
\hline $\mathrm{h}_{5}{ }^{-1} \mathrm{~K}_{\mathrm{A} 1}: \mathrm{A} 1 \rightarrow \mathrm{C} 2$ & $\mathrm{~h}_{5}{ }^{-1} \mathrm{~K}_{\mathrm{A} 1} \mathrm{~h}_{1}: \mathrm{B} 1 \rightarrow \mathrm{C} 2$ & $\mathrm{~h}_{5}{ }^{-1} \mathrm{~K}_{\mathrm{A} 1} \mathrm{~h}_{2}: \mathrm{C} 1 \rightarrow \mathrm{C} 2$ & $\mathrm{~h}_{5}{ }^{-1} \mathrm{~K}_{\mathrm{A} 1} \mathrm{~h}_{3}: \mathrm{A} 2 \rightarrow \mathrm{C} 2$ & $\mathrm{~h}_{5}{ }^{-1} \mathrm{~K}_{\mathrm{A} 1} \mathrm{~h}_{4}: \mathrm{B} 2 \rightarrow \mathrm{C} 2$ & $\mathrm{~h}_{5}{ }^{-1} \mathrm{~K}_{\mathrm{A} 1} \mathrm{~h}_{5}=\mathrm{K}_{\mathrm{C} 2}$ \\
\hline
\end{tabular}

629 Table 2. The 40 operations appearing in the space groupoid of sepiolite. Fr. is the occurrence 630 frequency of the corresponding operation, i.e. the number of hybrid groups in which the operation 631 occurs. Operations No. 1, 8, 13, 16, 21, 28, 33 and 36 in this list occur six times, i.e. in each of the 632 hybrid group, and are therefore global operations. These are the coset representatives of the 633 operations of $\mathrm{Pbcn}$, the space-group type of sepiolite, as well as the defining operations of the 634 corresponding symmetry elements.

\begin{tabular}{|c|c|c|c|c|c|c|c|c|c|c|c|}
\hline No & Op. & $\mathrm{Fr}$ & No & Op. & $\mathrm{Fr}$ & No & Op. & $\mathrm{Fr}$ & No & Op. & $\mathrm{Fr}$ \\
\hline 1 & 1 & 6 & 11 & $2_{1} x, 0.171,1 / 4$ & 4 & 21 & $21 / 2, y, 1 / 2$ & 6 & 31 & $2,1 / 4,0.171, z$ & 4 \\
\hline 2 & $\mathrm{t}(0,0.158,0.5)$ & 4 & 12 & $2{ }_{1} x, 0.329,1 / 4$ & 4 & 22 & $2(0,0.158,0) \frac{1}{2}, y, 1 / 2$ & 4 & 32 & $2,1 / 4,0.329, z$ & 4 \\
\hline 3 & $\mathrm{t}(0,-0.158,0.5)$ & 4 & 13 & $2, x, 1 / 4,1 / 4$ & 6 & 23 & $2(0,0 .-158,0) \frac{1}{2}, y, 1 / 2$ & 4 & 33 & $22_{2}^{1 / 4,1 / 4,, z}$ & 6 \\
\hline 4 & $\mathrm{t}(0,-0.316,0.5)$ & 2 & 14 & $22_{1} x, 0.092,1 / 4$ & 2 & 24 & $2(0,-0.316,0) \frac{1}{2}, y, 1 / 2$ & 2 & 34 & $2{ }_{2} 1 / 4,0.092, z$ & 2 \\
\hline 5 & $\mathrm{t}(0,0.316,0.5)$ & 2 & 15 & $22_{1} x, 0.408,1 / 4$ & 2 & 25 & $2(0,0.316,0) \quad 1 / 2, y, 1 / 2$ & 2 & 35 & $2{ }_{2} 1 / 4,0.408, z$ & 2 \\
\hline 6 & $\overline{1}_{1 / 2}, 0.421,1 / 2$ & 4 & 16 & $n^{1 / 4, y, z}$ & 6 & 26 & $m x, 0.421, z$ & 4 & 36 & $n x, y, 1 / 4$ & 6 \\
\hline 7 & $\overline{1} 1 / 2,0.579,1 / 2$ & 4 & 17 & $g(0,0.658,1) 1 / 4, y, z$ & 4 & 27 & $m x, 0.579, z$ & 4 & 37 & $g(1 / 2,0.658,0) \quad x, y, 1 / 4$ & 4 \\
\hline 8 & $\overline{1}_{1 / 2,1 / 2,1 / 2}$ & 6 & 18 & $g(0,0.342,1) 1 / 4, y, z$ & 4 & 28 & $c x, 1 / 2, z$ & 6 & 38 & $g(1 / 2,0.342,0) \quad x, y, 1 / 4$ & 4 \\
\hline 9 & $\overline{1}_{1 / 2,0.342,1 / 2}$ & 2 & 19 & $g(0,0.184,1 / 2) 1 / 4, y, z$ & 2 & 29 & $c x, 0.342, z$ & 2 & 39 & $g(1 / 2,0.184,0) \quad x, y, 1 / 4$ & 2 \\
\hline 10 & $\overline{1}_{1 / 2}, 0.658,1 / 2$ & 2 & 20 & $g(0,0.816,1 / 2) 1 / 4, y, z$ & 2 & 30 & $c x, 0.658, z$ & 2 & 40 & $g(1 / 2,0.816,0) \quad x, y, 1 / 4$ & 2 \\
\hline
\end{tabular}

635 Table 3. Space groupoid of sepiolite, with the operations synthetically indicated by the sequence 636 number in Table 2. In bold the operations occurring in every hybrid group: these are global 637 operations which build the space group of the mineral.

\begin{tabular}{|l|l|l|l|l|l|l|}
\hline $\mathrm{M}_{\mathrm{A} 1}$ & $\mathbf{1 , 8 , 2 1 , 2 8}$ & $2,6,22,26$ & $3,7,27,23$ & $\mathbf{1 3 , 1 6 , 3 3 , 3 6}$ & $11,17,31,37$ & $12,18,32,38$ \\
\hline $\mathrm{M}_{\mathrm{B} 1}$ & $3,6,23,26$ & $\mathbf{1 , 9 , 2 1 , 2 9}$ & $4, \mathbf{8 , 2 4 , 2 8}$ & $11,18,31,38$ & $14, \mathbf{1 6 , 3 4 , 3 6}$ & $\mathbf{1 3 , 1 9 , 3 3 , 3 9}$ \\
\hline $\mathrm{M}_{\mathrm{C} 1}$ & $2,7,22,27$ & $5, \mathbf{8}, 25, \mathbf{2 8}$ & $\mathbf{1 , 1 0 , 2 1 , 3 0}$ & $12,17,32,37$ & $\mathbf{1 3 , 2 0 , 3 3 , 4 0}$ & $15, \mathbf{1 6}, 35, \mathbf{3 6}$ \\
\hline $\mathrm{M}_{\mathrm{A} 2}$ & $\mathbf{1 3 , 1 6 , 3 3 , 3 6}$ & $11,17,31,37$ & $12,18,32,38$ & $\mathbf{1 , 8 , 2 1 , 2 8}$ & $2,6,22,26$ & $3,7,23,27$ \\
\hline $\mathrm{M}_{\mathrm{B} 2}$ & $11,18,31,38$ & $14, \mathbf{1 6}, 24, \mathbf{3 6}$ & $\mathbf{1 3 , 1 9 , 3 3 , 3 9}$ & $3,6,23,26$ & $\mathbf{1 , 9 , 2 1 , 2 9}$ & $4, \mathbf{8 , 2 4 , 2 8}$ \\
\hline $\mathrm{M}_{\mathrm{C} 2}$ & $12,17,32,37$ & $\mathbf{1 3 , 2 0 , 3 3 , 4 0}$ & $15, \mathbf{1 6}, 35, \mathbf{3 6}$ & $2,7,22,27$ & $5, \mathbf{8}, 25, \mathbf{2 8}$ & $\mathbf{1 , 1 0 , 2 1 , 3 0}$ \\
\hline
\end{tabular}


638 Table 4. Space groupoid construction for jimthompsonite. $\mathrm{K}_{\mathrm{X}}$ is the kernel of the $\mathrm{X} \operatorname{rod} R_{2}(\mathrm{X}=\mathrm{A} 1$, $639 \mathrm{~B} 1, \mathrm{C} 1, \mathrm{~A} 2$, B2, C2, the partial operations are $\mathrm{h}_{1}(\mathrm{~B} 1 \rightarrow \mathrm{A} 1): m_{x, 0.6662, z ;} ; \mathrm{h}_{2}(\mathrm{C} 1 \rightarrow \mathrm{A} 1): m_{x .0 .83407, z} ; \mathrm{h}_{3}$ $640(\mathrm{~A} 2 \rightarrow \mathrm{A} 1): b_{1 / 4, y, z} ; \mathrm{h}_{4}(\mathrm{~B} 2 \rightarrow \mathrm{A} 1)=\mathrm{h}_{1} \mathrm{~h}_{3}=2_{1 / 1 / 0.4162, z} ; \mathrm{h}_{5}(\mathrm{C} 2 \rightarrow \mathrm{A} 1)=\mathrm{h}_{2} \mathrm{~h}_{3}=2_{1 / 4,0.58407, z}, \mathrm{~h}_{6}(\mathrm{~A} 3 \rightarrow$ $641 \mathrm{~A} 1): a_{x, y, 1 / 4} ; \mathrm{h}_{7}(\mathrm{~B} 3 \rightarrow \mathrm{A} 1)=\mathrm{h}_{1} \mathrm{~h}_{6}=2_{1 x, 0.6662,1 / 4} ; \mathrm{h}_{8}(\mathrm{C} 3 \rightarrow \mathrm{A} 1)=\mathrm{h}_{2} \mathrm{~h}_{6}=2_{1 x, 0.83407,1 / 4} ; \mathrm{h}_{9}(\mathrm{~A} 4 \rightarrow \mathrm{A} 1): \overline{1}_{1 / 2,1 / 2,1 / 2} ;$ $642 \mathrm{~h}_{10}(\mathrm{~B} 4 \rightarrow \mathrm{A} 1)=\mathrm{h}_{1} \mathrm{~h}_{9}=2(0,0.3324,0)_{\frac{1}{2}, y, 0} ; \mathrm{h}_{11}(\mathrm{C} 4 \rightarrow \mathrm{A} 1)=\mathrm{h}_{2} \mathrm{~h}_{9}=2(0,0.66814,0)_{1 / 2, y, 0}$.

\begin{tabular}{|c|c|c|c|c|c|c|c|c|c|c|c|}
\hline $\begin{array}{l}\mathrm{K}_{\mathrm{A} 1} \\
\mathrm{~A} 1 \rightarrow \mathrm{A} 1\end{array}$ & $\begin{array}{l}\mathrm{K}_{\mathrm{A} 1} \mathrm{~h}_{1} \\
\mathrm{~B} 1 \rightarrow \mathrm{A} 1\end{array}$ & $\begin{array}{l}\mathrm{K}_{\mathrm{A} 1} \mathrm{~h}_{2} \\
\mathrm{C} 1 \rightarrow \mathrm{A} 1\end{array}$ & $\begin{array}{l}\mathrm{K}_{\mathrm{A} 1} \mathrm{~h}_{3} \\
\mathrm{~A} 2 \rightarrow \mathrm{A} 1\end{array}$ & $\begin{array}{l}\mathrm{K}_{\mathrm{A} 1} \mathrm{~h}_{4} \\
\mathrm{~B} 2 \rightarrow \mathrm{A} 1\end{array}$ & $\begin{array}{l}\mathrm{K}_{\mathrm{A} 1} \mathrm{~h}_{5} \\
\mathrm{C} 2 \rightarrow \mathrm{A} 1\end{array}$ & $\begin{array}{l}\mathrm{K}_{\mathrm{A} 1} \mathrm{~h}_{6} \\
\mathrm{~A} 3 \rightarrow \mathrm{A} 1\end{array}$ & $\begin{array}{l}\mathrm{K}_{\mathrm{A} 1} \mathrm{~h}_{7} \\
\mathrm{~B} 3 \rightarrow \mathrm{A} 1\end{array}$ & $\begin{array}{l}\mathrm{K}_{\mathrm{A} 1} \mathrm{~h}_{8} \\
\mathrm{C} 3 \rightarrow \mathrm{A} 1\end{array}$ & $\begin{array}{l}\mathrm{K}_{\mathrm{A} 1} \mathrm{~h}_{9} \\
\mathrm{~A} 4 \rightarrow \mathrm{A} 1\end{array}$ & $\mathrm{~B} 4 \rightarrow \mathrm{A} 1$ & $\begin{array}{l}\mathrm{C}_{\mathrm{A} 1} \mathrm{~h}_{11} \\
\mathrm{C} 4 \rightarrow \mathrm{A} 1\end{array}$ \\
\hline $\mathrm{h}_{1}{ }^{-1} \mathrm{~K}_{\mathrm{A} 1}$ & $\mathrm{~h}_{1}^{-1} \mathrm{~K}_{\mathrm{Al}} \mathrm{h}_{1}$ & ${ }^{-1} \mathrm{~K}_{\mathrm{A} 1} \mathrm{~h}_{2}$ & ${ }^{-1} \mathrm{~K}_{\mathrm{A} 1} \mathrm{~h}_{3}$ & $\mathrm{~h}_{1}{ }^{-1} \mathrm{~K}_{\mathrm{A} 1} \mathrm{~h}_{4}$ & $\mathrm{~h}_{1}{ }^{-1} \mathrm{~K}_{\mathrm{A} 1} \mathrm{~h}_{5}$ & $\mathrm{~h}_{1}^{-1} \mathrm{~K}_{\mathrm{A} 1} \mathrm{~h}_{6}$ & ${ }_{1}^{-1} \mathrm{~K}_{\mathrm{A} 1} \mathrm{~h}_{7}$ & ${ }^{-1} \mathrm{~K}_{\mathrm{A} 1} \mathrm{~h}_{8}$ & $\mathrm{~h}_{1}^{-1} \mathrm{~K}_{\mathrm{A} 1} \mathrm{~h}_{9}$ & & $\mathrm{~h}_{1}^{-1} \mathrm{~K}_{\mathrm{A} 1} \mathrm{~h}_{11}$ \\
\hline $\mathrm{A} 1 \rightarrow \mathrm{B} 1$ & $\mathrm{~B} 1 \rightarrow \mathrm{B} 1$ & $\mathrm{C} 1 \rightarrow \mathrm{B} 1$ & $\mathrm{~A} 2 \rightarrow \mathrm{B} 1$ & $\mathrm{~B} 2 \rightarrow \mathrm{B} 1$ & $\mathrm{C} 2 \rightarrow \mathrm{B} 1$ & & $\mathrm{~B} 3 \rightarrow \mathrm{B} 1$ & $\mathrm{C} 3 \rightarrow \mathrm{B} 1$ & $\mathrm{~A} 4 \rightarrow \mathrm{B} 1$ & & $\mathrm{C} 4 \rightarrow \mathrm{B} 1$ \\
\hline $\mathrm{h}_{2}^{-1} \mathrm{~K}_{\mathrm{A} 1}$ & ${ }_{2}^{-1} \mathrm{~K}_{\mathrm{A} 1} \mathrm{~h}_{1}$ & ${ }^{-1} \mathrm{~K}_{\mathrm{A} 1} \mathrm{~h}_{2}$ & ${ }^{1} \mathrm{~K}_{\mathrm{A} 1} \mathrm{~h}_{3}$ & $\mathrm{~h}_{2}^{-1} \mathrm{~K}_{\mathrm{A} 1} \mathrm{~h}_{4}$ & $\mathrm{~h}_{2}^{-1} \mathrm{~K}_{\mathrm{Al}} \mathrm{h}_{5}$ & $\mathrm{~h}_{2}^{-1} \mathrm{~K}_{\mathrm{Al}} \mathrm{h}_{6}$ & ${ }_{2}^{-1} \mathrm{~K}_{\mathrm{A} 1} \mathrm{~h}_{7}$ & ${ }^{-1} \mathrm{~K}_{\mathrm{A} 1} \mathrm{~h}_{8}$ & ${ }_{2}^{-1} \mathrm{~K}_{\mathrm{Al}} \mathrm{h}_{9}$ & $2^{-1} \mathrm{~K}_{t}$ & $\mathrm{~h}_{2}^{-1} \mathrm{~K}_{\mathrm{Al}} \mathrm{h}_{11}$ \\
\hline $\mathrm{A} 1 \rightarrow \mathrm{C} 1$ & $\mathrm{~B} 1 \rightarrow \mathrm{C} 1$ & $\mathrm{C} 1 \rightarrow \mathrm{C} 1$ & $\mathrm{~A} 2 \rightarrow \mathrm{C} 1$ & $\mathrm{~B} 2 \rightarrow \mathrm{C} 1$ & $\mathrm{C} 2 \rightarrow \mathrm{C} 1$ & $\mathrm{~A} 3 \rightarrow \mathrm{C} 1$ & $\mathrm{~B} 3 \rightarrow \mathrm{C} 1$ & $\mathrm{C} 3 \rightarrow \mathrm{C} 1$ & $\mathrm{~A} 4 \rightarrow \mathrm{C} 1$ & $\mathrm{~B} 4 \rightarrow \mathrm{C} 1$ & $\mathrm{C} 4 \rightarrow \mathrm{C} 1$ \\
\hline $\mathrm{h}_{3}^{-1} \mathrm{~K}_{\mathrm{A} 1}$ & ${ }^{-1} \mathrm{~K}_{\mathrm{A} 1} \mathrm{~h}_{1}$ & ${ }_{3}{ }^{-1} \mathrm{~K}_{\mathrm{A} 1} \mathrm{~h}_{2}$ & $\mathrm{1}_{3}{ }^{-1} \mathrm{~K}_{\mathrm{A} 1} \mathrm{~h}_{3}$ & $\mathrm{~h}_{3}{ }^{-1} \mathrm{~K}_{\mathrm{A} 1} \mathrm{~h}_{4}$ & $\mathrm{~h}_{3}{ }^{-1} \mathrm{~K}_{\mathrm{A} 1} \mathrm{~h}_{5}$ & $\mathrm{~h}_{3}{ }^{-1} \mathrm{~K}_{\mathrm{A} 1} \mathrm{~h}_{6}$ & $\mathrm{~h}_{3}{ }^{-1} \mathrm{~K}_{\mathrm{A} 1} \mathrm{~h}_{7}$ & $\mathrm{~h}_{3}^{-1} \mathrm{~K}_{\mathrm{A} 1} \mathrm{~h}_{8}$ & $\mathrm{~h}_{3}^{-1} \mathrm{~K}_{\mathrm{Al}} \mathrm{h}_{9}$ & $\mathrm{~h}_{3}{ }^{-1} \mathrm{~K}_{\mathrm{A} 1} \mathrm{~h}_{10}$ & $\mathrm{~h}_{3}^{-1} \mathrm{~K}_{\mathrm{Al}} \mathrm{h}_{11}$ \\
\hline $\mathrm{A} 1 \rightarrow \mathrm{A} 2$ & $\mathrm{~B} 1 \rightarrow \mathrm{A} 2$ & $\mathrm{C} 1 \rightarrow \mathrm{A} 2$ & & $\mathrm{~B} 2 \rightarrow \mathrm{A} 2$ & $\mathrm{C} 2 \rightarrow \mathrm{A} 2$ & $\mathrm{~A} 3 \rightarrow \mathrm{A} 2$ & $\mathrm{~B} 3 \rightarrow \mathrm{A} 2$ & $\mathrm{C} 3 \rightarrow \mathrm{A} 2$ & $\mathrm{~A} 4 \rightarrow \mathrm{A} 2$ & & $\mathrm{C} 4 \rightarrow \mathrm{A} 2$ \\
\hline $\mathrm{h}_{4}^{-1} \mathrm{~K}_{\mathrm{A} 1}$ & ${ }_{4}^{-1} \mathrm{~K}_{\mathrm{A} 1} \mathrm{~h}_{1}$ & ${ }^{1} \mathrm{~K}_{\mathrm{Al}} \mathrm{h}_{2}$ & ${ }^{-1} \mathrm{~K}_{\mathrm{A} 1} \mathrm{~h}_{3}$ & $\mathrm{~h}_{4}^{-1} \mathrm{~K}_{\mathrm{A} 1} \mathrm{~h}_{4}$ & $\mathrm{~h}_{4}^{-1} \mathrm{~K}_{\mathrm{Al}} \mathrm{h}_{5}$ & ${ }^{-1} \mathrm{~K}_{\mathrm{A} 1} \mathrm{~h}_{6}$ & ${ }_{4}^{-1} \mathrm{~K}_{\mathrm{A} 1} \mathrm{~h}_{7}$ & ${ }_{4}^{-1} \mathrm{~K}_{\mathrm{A} 1} \mathrm{~h}_{8}$ & $\mathrm{~h}_{4}^{-1} \mathrm{~K}_{\mathrm{Al}} \mathrm{h}_{9}$ & 110 & $\mathrm{~h}_{4}^{-1} \mathrm{~K}_{\mathrm{A} 1} \mathrm{~h}_{11}$ \\
\hline $\mathrm{A} 1 \rightarrow \mathrm{B} 2$ & $\mathrm{~B} 1 \rightarrow \mathrm{B} 2$ & $\mathrm{C} 1 \rightarrow \mathrm{B} 2$ & $\mathrm{~A} 2 \rightarrow \mathrm{B} 2$ & $\mathrm{~B} 2 \rightarrow \mathrm{B} 2$ & $\mathrm{C} 2 \rightarrow \mathrm{B} 2$ & $\mathrm{~A} 3 \rightarrow \mathrm{B} 2$ & $\mathrm{~B} 3 \rightarrow \mathrm{B} 2$ & $\mathrm{C} 3 \rightarrow \mathrm{B} 2$ & $\mathrm{~A} 4 \rightarrow \mathrm{B} 2$ & $\mathrm{~B} 4 \rightarrow \mathrm{B} 2$ & $\mathrm{C} 4 \rightarrow \mathrm{B} 2$ \\
\hline & & & & & & & & & & & \\
\hline $\mathrm{A} 1 \rightarrow \mathrm{C} 2$ & $\mathrm{~B} 1 \rightarrow \mathrm{C} 2$ & $\mathrm{C} 1 \rightarrow \mathrm{C} 2$ & $\mathrm{~A} 2 \rightarrow \mathrm{C} 2$ & $\mathrm{~B} 2 \rightarrow \mathrm{C} 2$ & $\mathrm{C} 2 \rightarrow \mathrm{C} 2$ & $\mathrm{~A} 3 \rightarrow \mathrm{C} 2$ & $\mathrm{~B} 3 \rightarrow \mathrm{C} 2$ & $\mathrm{C} 3 \rightarrow \mathrm{C} 2$ & $\mathrm{~A} 4 \rightarrow \mathrm{C} 2$ & & $\mathrm{C} 4 \rightarrow \mathrm{C} 2$ \\
\hline $\mathrm{h}_{6}^{-1} \mathrm{~K}_{\mathrm{A} 1}$ & $\mathrm{~h}_{6}{ }^{-1} \mathrm{~K}_{\mathrm{Al}} \mathrm{h}_{1}$ & $\mathrm{~h}_{6}{ }^{-1} \mathrm{~K}_{\mathrm{A} 1} \mathrm{~h}_{2}$ & $\mathrm{~h}_{6}{ }^{-1} \mathrm{~K}_{\mathrm{A} 1} \mathrm{~h}_{3}$ & $\mathrm{~h}_{6}{ }^{-1} \mathrm{~K}_{\mathrm{A} 1} \mathrm{~h}_{4}$ & $\mathrm{~h}_{6}{ }^{-1} \mathrm{~K}_{\mathrm{A} 1} \mathrm{~h}_{5}$ & $\mathrm{~h}_{6}^{-1} \mathrm{~K}_{\mathrm{Al}} \mathrm{h}_{6}$ & $\mathrm{~h}_{6}{ }^{-1} \mathrm{~K}_{\mathrm{Al}} \mathrm{h}_{7}$ & $\mathrm{~h}_{6}^{-1} \mathrm{~K}_{\mathrm{A} 1} \mathrm{~h}_{8}$ & $\mathrm{~h}_{6}{ }^{-1} \mathrm{~K}_{\mathrm{A} 1} \mathrm{~h}_{9}$ & $\mathrm{~h}_{6}{ }^{-1} \mathrm{~K}_{\mathrm{A} 1} \mathrm{~h}_{10}$ & $\mathrm{~h}_{6}^{-1} \mathrm{~K}_{\mathrm{Al}} \mathrm{h}_{11}$ \\
\hline $\mathrm{A} 1 \rightarrow \mathrm{A} 3$ & $\mathrm{~B} 1 \rightarrow \mathrm{A} 3$ & & & & & & & & & & \\
\hline & & ${ }^{-1} \mathrm{~K}_{\mathrm{A} 1} \mathrm{~h}_{2}$ & $\mathrm{~h}_{7}^{-1} \mathrm{~K}_{\mathrm{A} 1} \mathrm{~h}_{3}$ & $\mathrm{~h}_{7}^{-1} \mathrm{~K}_{\mathrm{Al}} \mathrm{h}_{4}$ & $\mathrm{~h}_{7}^{-1} \mathrm{~K}_{\mathrm{Al}} \mathrm{h}_{5}$ & $\mathrm{~h}_{7}^{-1} \mathrm{~K}_{\mathrm{A} 1} \mathrm{~h}_{6}$ & ${ }_{7}^{-1} \mathrm{~K}_{\mathrm{A} 1} \mathrm{~h}_{7}$ & & $\mathrm{~h}_{7}^{-1} \mathrm{~K}_{\mathrm{A} 1} \mathrm{~h}_{9}$ & & \\
\hline $\mathrm{A} 1 \rightarrow \mathrm{B} 3$ & $\mathrm{~B} 1 \rightarrow \mathrm{B} 3$ & $\mathrm{C} 1 \rightarrow \mathrm{B} 3$ & $\mathrm{~A} 2 \rightarrow \mathrm{B} 3$ & $\mathrm{~B} 2 \rightarrow \mathrm{B} 3$ & $\mathrm{C} 2 \rightarrow \mathrm{B} 3$ & $\mathrm{~A} 3 \rightarrow \mathrm{B} 3$ & $\mathrm{~B} 3 \rightarrow \mathrm{B} 3$ & $\mathrm{C} 3 \rightarrow \mathrm{B} 3$ & $\mathrm{~A} 4 \rightarrow \mathrm{B} 3$ & & $\mathrm{C} 4 \rightarrow \mathrm{B} 3$ \\
\hline $\mathrm{h}_{8}{ }^{-1} \mathrm{~K}_{\mathrm{A} 1}$ & & & & & & & & & & $\mathrm{~h}_{8}^{-1} \mathrm{~K}_{\mathrm{Al}} \mathrm{h}_{10}$ & $\mathrm{~h}_{8}^{-1} \mathrm{~K}_{\mathrm{Al}} \mathrm{h}_{11}$ \\
\hline $\mathrm{A} 1 \rightarrow \mathrm{C} 3$ & $\mathrm{~B} 1 \rightarrow \mathrm{C} 3$ & & & & & & & & & & $\mathrm{C} 4 \rightarrow \mathrm{C} 3$ \\
\hline $\mathrm{h}_{9}{ }^{-1} \mathrm{~K}_{\mathrm{A} 1}$ & $\mathrm{~h}_{9}{ }^{-1} \mathrm{~K}_{\mathrm{A} 1} \mathrm{~h}_{1}$ & $\mathrm{~h}_{9}{ }^{-1} \mathrm{~K}_{\mathrm{A} 1} \mathrm{~h}_{2}$ & $\mathrm{~h}_{9}{ }^{-1} \mathrm{~K}_{\mathrm{A} 1} \mathrm{~h}_{3}$ & $\mathrm{~h}_{9}{ }^{-1} \mathrm{~K}_{\mathrm{A} 1} \mathrm{~h}_{4}$ & $\mathrm{~h}_{9}{ }^{-1} \mathrm{~K}_{\mathrm{A} 1} \mathrm{~h}_{5}$ & $\mathrm{~h}_{9}{ }^{-1} \mathrm{~K}_{\mathrm{A} 1} \mathrm{~h}_{6}$ & $\mathrm{~h}_{9}{ }^{-1} \mathrm{~K}_{\mathrm{A} 1} \mathrm{~h}_{7}$ & $\mathrm{~h}_{9}{ }^{-1} \mathrm{~K}_{\mathrm{A} 1} \mathrm{~h}_{8}$ & $\mathrm{~h}_{9}{ }^{-1} \mathrm{~K}_{\mathrm{A} 1} \mathrm{~h}_{9}$ & $\mathrm{~h}_{9}^{-1} \mathrm{~K}_{\mathrm{Al}} \mathrm{h}_{10}$ & $\mathrm{~h}_{9}^{-1} \mathrm{~K}_{\mathrm{A1}} \mathrm{h}_{11}$ \\
\hline $\mathrm{A} 1 \rightarrow \mathrm{A} 4$ & $\mathrm{~B} 1 \rightarrow \mathrm{A} 4$ & $\mathrm{C} 1 \rightarrow \mathrm{A} 4$ & $\mathrm{~A} 2 \rightarrow \mathrm{A} 4$ & $\mathrm{~B} 2 \rightarrow \mathrm{A} 4$ & $\mathrm{C} 2 \rightarrow \mathrm{A} 4$ & $\mathrm{~A} 3 \rightarrow \mathrm{A} 4$ & $\mathrm{~B} 3 \rightarrow \mathrm{A} 4$ & $\mathrm{C} 3 \rightarrow \mathrm{A} 4$ & $\mathrm{~A} 4 \rightarrow \mathrm{A} 4$ & $\mathrm{~B} 4 \rightarrow \mathrm{A} 4$ & $\mathrm{C} 4 \rightarrow \mathrm{A} 4$ \\
\hline $\mathrm{h}_{10}{ }^{-1} \mathrm{~K}_{\mathrm{A} 1}$ & $\mathrm{~h}_{10}{ }^{-1} \mathrm{~K}_{\mathrm{Al}} \mathrm{h}_{1}$ & $\mathrm{~h}_{10}{ }^{-1} \mathrm{~K}_{\mathrm{A} 1} \mathrm{~h}_{2}$ & $0^{-1} \mathrm{~K}_{\mathrm{Al}} \mathrm{h}_{3}$ & $\mathrm{~h}_{10}{ }^{-1} \mathrm{~K}_{\mathrm{A} 1} \mathrm{~h}_{4}$ & $\mathrm{~h}_{10}{ }^{-1} \mathrm{~K}_{\mathrm{A} 1} \mathrm{~h}_{5}$ & $\mathrm{~h}_{10}{ }^{-1} \mathrm{~K}_{\mathrm{A} 1} \mathrm{~h}_{6}$ & $\mathrm{~h}_{10}{ }^{-1} \mathrm{~K}_{\mathrm{Al}} \mathrm{h}_{7}$ & & $\mathrm{~h}_{10}{ }^{-1} \mathrm{~K}_{\mathrm{A} 1} \mathrm{~h}_{9}$ & $\mathrm{~h}_{10}{ }^{-1} \mathrm{~K}_{\mathrm{A} \mathbf{1}} \mathbf{h}_{10}$ & $\mathrm{~h}_{10}{ }^{-1} \mathrm{~K}_{\mathrm{A} 1} \mathrm{~h}_{11}$ \\
\hline $\mathrm{A} 1 \rightarrow \mathrm{B} 4$ & $\mathrm{~B} 1 \rightarrow \mathrm{B} 4$ & & $\mathrm{~A} 2 \rightarrow \mathrm{B} 4$ & $\mathrm{~B} 2 \rightarrow \mathrm{B} 4$ & & & & $\mathrm{C} 3 \rightarrow \mathrm{B} 4$ & $\mathrm{~A} 4 \rightarrow \mathrm{B} 4$ & $\mathrm{~B} 4 \rightarrow \mathrm{B} 4$ & $\mathrm{C} 4 \rightarrow \mathrm{B} 4$ \\
\hline $\mathrm{h}_{11}^{-1} \mathrm{~K}_{\mathrm{Al}}$ & $\mathrm{h}_{11}^{-1} \mathrm{~K}_{\mathrm{Al}} \mathrm{h}_{1}$ & $\mathrm{~h}_{1}^{-11} \mathrm{~K}_{\mathrm{A} 1} \mathrm{~h}_{2}$ & $\mathrm{~h}_{11}{ }^{-1} \mathrm{~K}_{\mathrm{A} 1} \mathrm{~h}_{3}$ & $\mathrm{~h}_{11}{ }^{-1} \mathrm{~K}_{\mathrm{A} 1} \mathrm{~h}_{4}$ & $\mathrm{~h}_{11}^{-1} \mathrm{~K}_{\mathrm{Al}} \mathrm{h}_{5}$ & $\mathrm{~h}_{1}{ }^{-11} \mathrm{~K}_{\mathrm{Al}} \mathrm{h}_{6}$ & $\mathrm{~h}_{11}^{-1} \mathrm{~K}_{\mathrm{Al}} \mathrm{h}_{7}$ & $\mathrm{~h}_{11}^{-1} \mathrm{~K}_{\mathrm{Al}} \mathrm{h}_{8}$ & $\mathrm{~h}_{11}{ }^{-1} \mathrm{~K}_{\mathrm{A} 1} \mathrm{~h}_{9}$ & $\mathrm{~h}_{11}^{-1} \mathrm{~K}_{\mathrm{Al}} \mathrm{h}_{10}$ & $\mathrm{~h}_{11}{ }^{-1} \mathrm{~K}_{\mathrm{A} 1} \mathrm{~h}_{11}$ \\
\hline $\mathrm{A} 1 \rightarrow \mathrm{C} 4$ & $\mathrm{~B} 1 \rightarrow \mathrm{C} 4$ & $\mathrm{C} 1 \rightarrow \mathrm{C} 4$ & $\mathrm{~A} 2 \rightarrow \mathrm{C} 4$ & $\mathrm{~B} 2 \rightarrow \mathrm{C} 4$ & $\mathrm{C} 2 \rightarrow \mathrm{C} 4$ & $\mathrm{~A} 3 \rightarrow \mathrm{C} 4$ & $\mathrm{~B} 3 \rightarrow \mathrm{C} 4$ & $\mathrm{C} 3 \rightarrow \mathrm{C} 4$ & $\mathrm{~A} 4 \rightarrow \mathrm{C} 4$ & $\mathrm{~B} 4 \rightarrow \mathrm{C} 4$ & $\mathrm{C} 4 \rightarrow \mathrm{C} 4$ \\
\hline
\end{tabular}


643 Table 5. The 40 operations appearing in the space groupoid of jimthompsonite. Fr. is the occurrence 644 frequency of the corresponding operation, i.e. the number of hybrid groups in which the operation 645 occurs. Operations No. 1,6,11,16,21,26,31 and 36 in this list occur six times, i.e. in each of the 646 hybrid groups, and are therefore global operations. These are the coset representatives of the 647 operations of $\mathrm{Pbca}$, the space-group type of jimthompsonite, as well as the defining operations of 648 the corresponding symmetry elements.

\begin{tabular}{|c|c|c|c|c|c|c|c|c|c|c|c|}
\hline No & Op. & $\mathrm{Fr}$ & No & Op. & $\mathrm{Fr}$ & No & Op. & $\mathrm{Fr}$ & No & Op. & $\mathrm{Fr}$ \\
\hline 1 & 1 & 12 & 11 & $2, x, 3 / 4,1 / 2$ & 12 & 21 & $2{ }_{3} 0, y, 1 / 4$ & 12 & 31 & $2,1 / 4,1 / 2, z$ & 12 \\
\hline 2 & $\mathrm{t}(0,0.16787,0.5)$ & 8 & 12 & $2_{\overline{1}} x, 0.666065,1 / 4$ & 8 & 22 & $2(0,1.33213,0) 0, y, 0$ & 8 & 32 & $2 \overline{1 / 4},-0.083935, z$ & 8 \\
\hline 3 & $\mathrm{t}(0,-0.16787,0.5)$ & 8 & 13 & $2_{\overline{1}} x, 0.833935,1 / 4$ & 8 & 23 & $2(0,1.66787,0) 0, y, 0$ & 8 & 33 & $2 \overline{1 / 4}, 0.083935, z$ & 8 \\
\hline 4 & $\mathrm{t}(0,-0.33574,0.5)$ & 4 & 14 & $2_{\bar{\top}} x, 0.58213,0$ & 4 & 24 & $2(0,1.16426,0) 0, y, 1 / 4$ & 4 & 34 & $2{ }_{1} \overline{1} / 4 .-0.16787, z$ & 4 \\
\hline 5 & $\mathrm{t}(0,0.335746,0.5)$ & 4 & 15 & $2_{\top} x, 0.91787,0$ & 4 & 25 & $2(0,1.83574,0) 0, y, 1 / 4$ & 4 & 35 & $2, \overline{1} / 4,0.16787, z$ & 4 \\
\hline 6 & $\overline{1} 0,0,0$ & 12 & 16 & $b^{1 / 4, y, z}$ & 12 & 26 & $c x, 3 / 4, z$ & 12 & 36 & $a x, y, 1 / 4$ & 12 \\
\hline 7 & $\overline{1} 0,0.083935, \overline{1} / 4$ & 8 & 17 & $g(0,-0.33213,1 / 2) 1 / 4, y, z$ & 8 & 27 & $m x, 0.666065, z$ & 8 & 37 & $g(\overline{1} / 2,0.16787,0) x, y, 0$ & 8 \\
\hline 8 & $\overline{1} 0,-0.083935, \overline{1} / 4$ & 8 & 18 & $g(0,-0.66787,1 / 2) 1 / 4, y, z$ & 8 & 28 & $m x, 0.8343935, z$ & 8 & 38 & $g(\overline{1 / 2},-0.16787) x, y, 0$ & 8 \\
\hline 9 & $\overline{1} 0,-0.16787,0$ & 4 & 19 & $g(0,0.16426,0) 1 / 4, y, z$ & 4 & 29 & c $x, 0.58213, z$ & 4 & 39 & $g(1 / 2,-0.33574,0) \quad x, y, 1 / 4$ & 4 \\
\hline 10 & $\overline{1} 0,0.16787,0$ & 4 & 20 & $g(0,0.83574,0) 1 / 4, y, z$ & 4 & 30 & c $x, 0.91787, z$ & 4 & 40 & $g(1 / 2,0.33574,0) \quad x, y, 1 / 4$ & 4 \\
\hline
\end{tabular}

649 Table 6. Space groupoid of jimthompsonite, with the operations synthetically indicated by the 650 sequence number in Table 5. In bold the operations occurring in every hybrid group: these are 651 global operations which build the space group of the mineral.

\begin{tabular}{|l|l|l|l|l|l|l|l|l|l|l|l|l|}
\hline $\mathrm{M}_{\mathrm{A} 1}$ & $\mathbf{1 , 2 6}$ & 2,27 & 3,28 & $\mathbf{1 6 , 3 1}$ & 17,32 & 18,33 & $\mathbf{1 1 , 3 6}$ & 12,37 & 13,38 & $\mathbf{6 , 2 1}$ & 7,22 & 8,23 \\
\hline $\mathrm{M}_{\mathrm{B} 1}$ & 3,27 & $\mathbf{1 , 2 9}$ & $4, \mathbf{2 6}$ & 18,32 & $\mathbf{1 6 , 3 4}$ & $19, \mathbf{3 1}$ & 12,38 & $14, \mathbf{3 6}$ & $\mathbf{1 1 , 3 9}$ & 8,22 & $\mathbf{6 , 2 4}$ & $9, \mathbf{2 1}$ \\
\hline $\mathrm{M}_{\mathrm{C} 1}$ & 2,28 & $5, \mathbf{2 6}$ & $\mathbf{1 , 3 0}$ & 17,33 & $20, \mathbf{3 1}$ & $\mathbf{1 6 , 3 5}$ & 13,37 & $\mathbf{1 1 , 4 0}$ & $15, \mathbf{3 6}$ & 7,23 & $10, \mathbf{2 1}$ & $\mathbf{6 , 2 5}$ \\
\hline $\mathrm{M}_{\mathrm{A} 2}$ & $\mathbf{1 6 , 3 1}$ & 17,32 & 18,33 & $\mathbf{1 , 2 6}$ & 2,27 & 3,28 & $\mathbf{6 , 2 1}$ & 8,23 & 7,22 & $\mathbf{1 1 , 3 6}$ & 13,38 & 12,37 \\
\hline $\mathrm{M}_{\mathrm{B} 2}$ & 18,32 & $\mathbf{1 6 , 3 4}$ & $19, \mathbf{3 1}$ & 3,27 & $\mathbf{1 , 2 9}$ & $4, \mathbf{2 6}$ & 8,22 & $9, \mathbf{2 1}$ & $\mathbf{6 , 2 4}$ & 12,38 & $\mathbf{1 1 , 3 9}$ & $14, \mathbf{3 6}$ \\
\hline $\mathrm{M}_{\mathrm{C} 2}$ & 17,33 & $20, \mathbf{3 1}$ & $\mathbf{1 6 , 3 5}$ & 2,28 & $5, \mathbf{2 6}$ & $\mathbf{1 , 3 0}$ & 7,23 & $\mathbf{6 , 2 5}$ & $10, \mathbf{2 1}$ & 13,37 & $15, \mathbf{3 6}$ & $\mathbf{1 1 , 4 0}$ \\
\hline $\mathrm{M}_{\mathrm{A} 3}$ & $\mathbf{1 1 , 3 6}$ & 12,37 & 13,38 & $\mathbf{6 , 2 1}$ & 8,23 & 7,22 & $\mathbf{1 , 2 6}$ & 2,27 & 3,28 & $\mathbf{1 , 3 1}$ & 18,33 & 17,32 \\
\hline $\mathrm{M}_{\mathrm{B} 3}$ & 12,38 & $14, \mathbf{3 6}$ & $\mathbf{1 1 , 3 9}$ & 8,22 & $9, \mathbf{2 1}$ & $\mathbf{6 , 2 4}$ & 2,27 & $\mathbf{1 , 2 9}$ & $4, \mathbf{2 6}$ & 18,32 & $19, \mathbf{3 1}$ & $\mathbf{1 6 , 3 4}$ \\
\hline $\mathrm{M}_{\mathrm{C} 3}$ & 13,37 & $\mathbf{1 1 , 4 0}$ & $15, \mathbf{3 6}$ & 7,23 & $\mathbf{6 , 2 5}$ & $10, \mathbf{2 1}$ & 2,28 & $5, \mathbf{2 6}$ & $\mathbf{1 , 3 0}$ & 17,33 & $\mathbf{1 6 , 3 5}$ & $20, \mathbf{3 1}$ \\
\hline $\mathrm{M}_{\mathrm{A} 4}$ & $\mathbf{6 , 2 1}$ & 7,22 & 8,23 & $\mathbf{1 1 , 3 6}$ & 13,38 & 12,37 & $\mathbf{1 6 , 3 1}$ & 18,33 & 17,32 & $\mathbf{1 , 2 6}$ & 2,27 & 3,28 \\
\hline $\mathrm{M}_{\mathrm{B} 4}$ & 8,22 & $\mathbf{6 , 2 4}$ & $9, \mathbf{2 1}$ & 12,38 & $\mathbf{1 1 , 3 9}$ & $14, \mathbf{3 6}$ & 18,32 & $19, \mathbf{3 1}$ & $\mathbf{1 6 , 3 4}$ & 3,27 & $\mathbf{1 , 2 9}$ & $4, \mathbf{2 6}$ \\
\hline $\mathrm{M}_{\mathrm{C} 4}$ & 7,23 & $10, \mathbf{2 1}$ & $\mathbf{6 , 2 5}$ & 13,37 & $15, \mathbf{3 6}$ & $\mathbf{1 1 , 4 0}$ & 17,33 & $\mathbf{1 6 , 3 5}$ & $20, \mathbf{3 1}$ & 2,28 & $5, \mathbf{2 6}$ & $\mathbf{1 , 3 0}$ \\
\hline
\end{tabular}




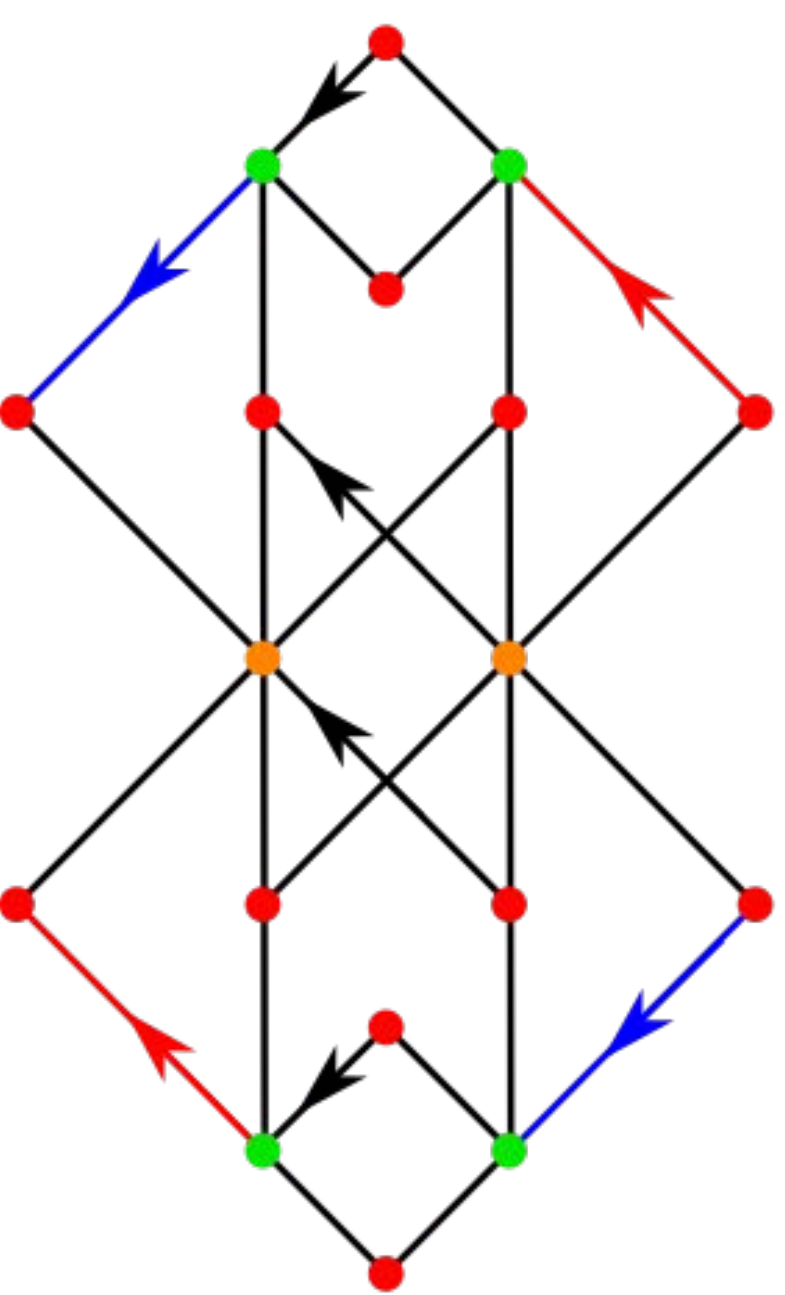

$a$

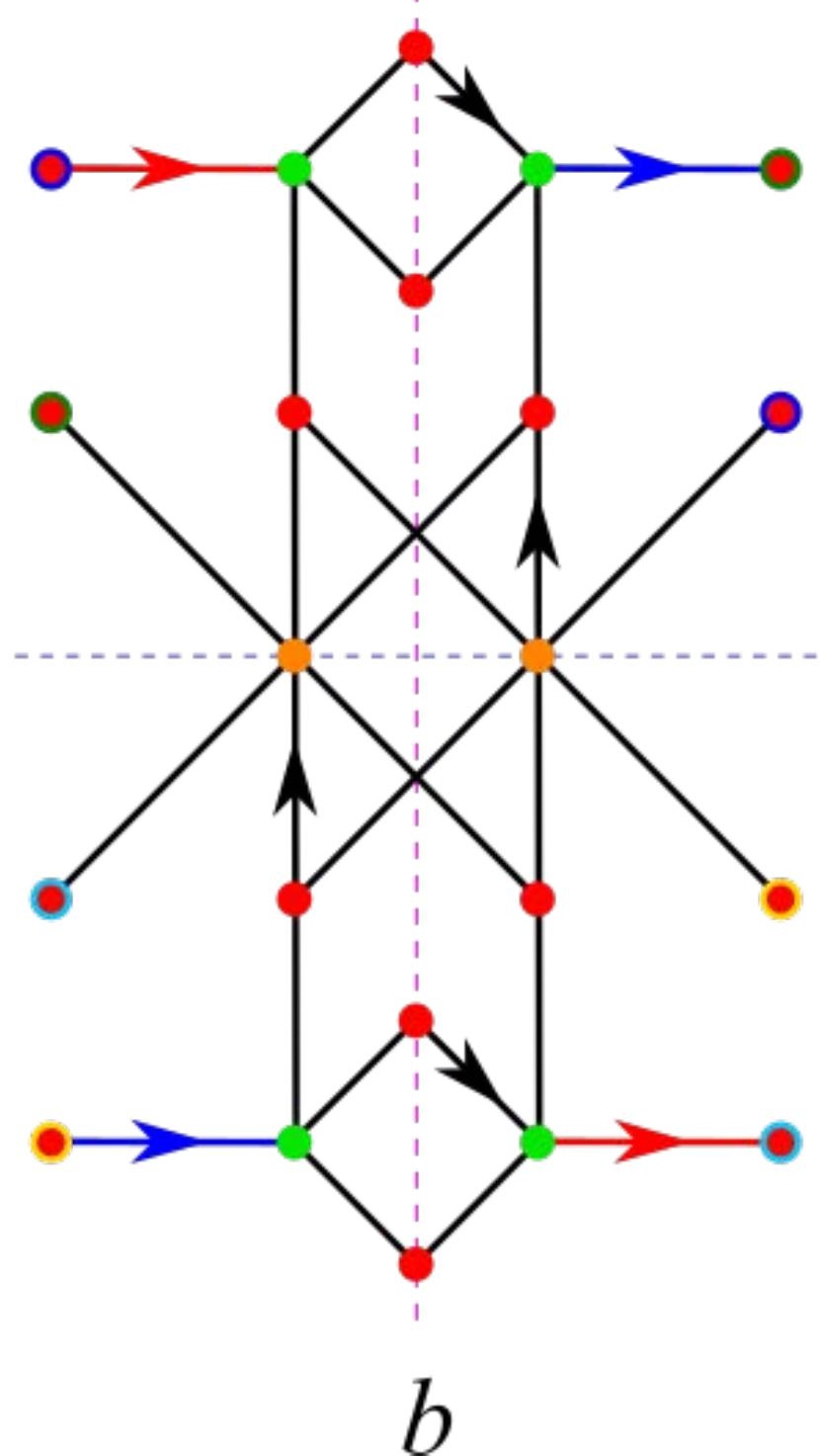




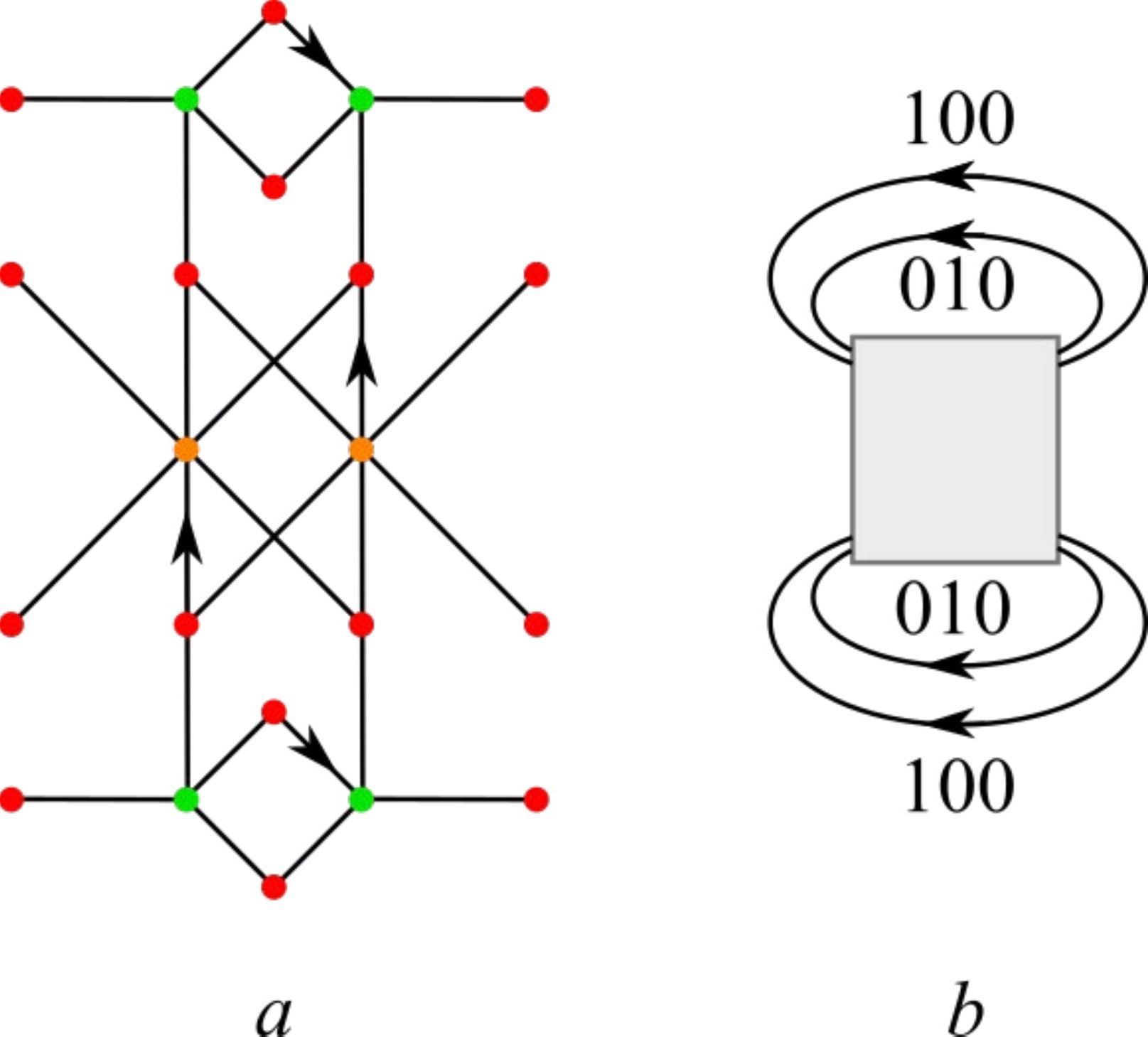




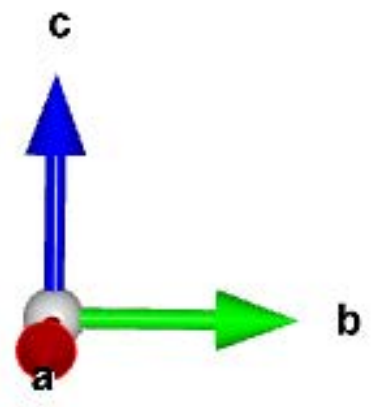




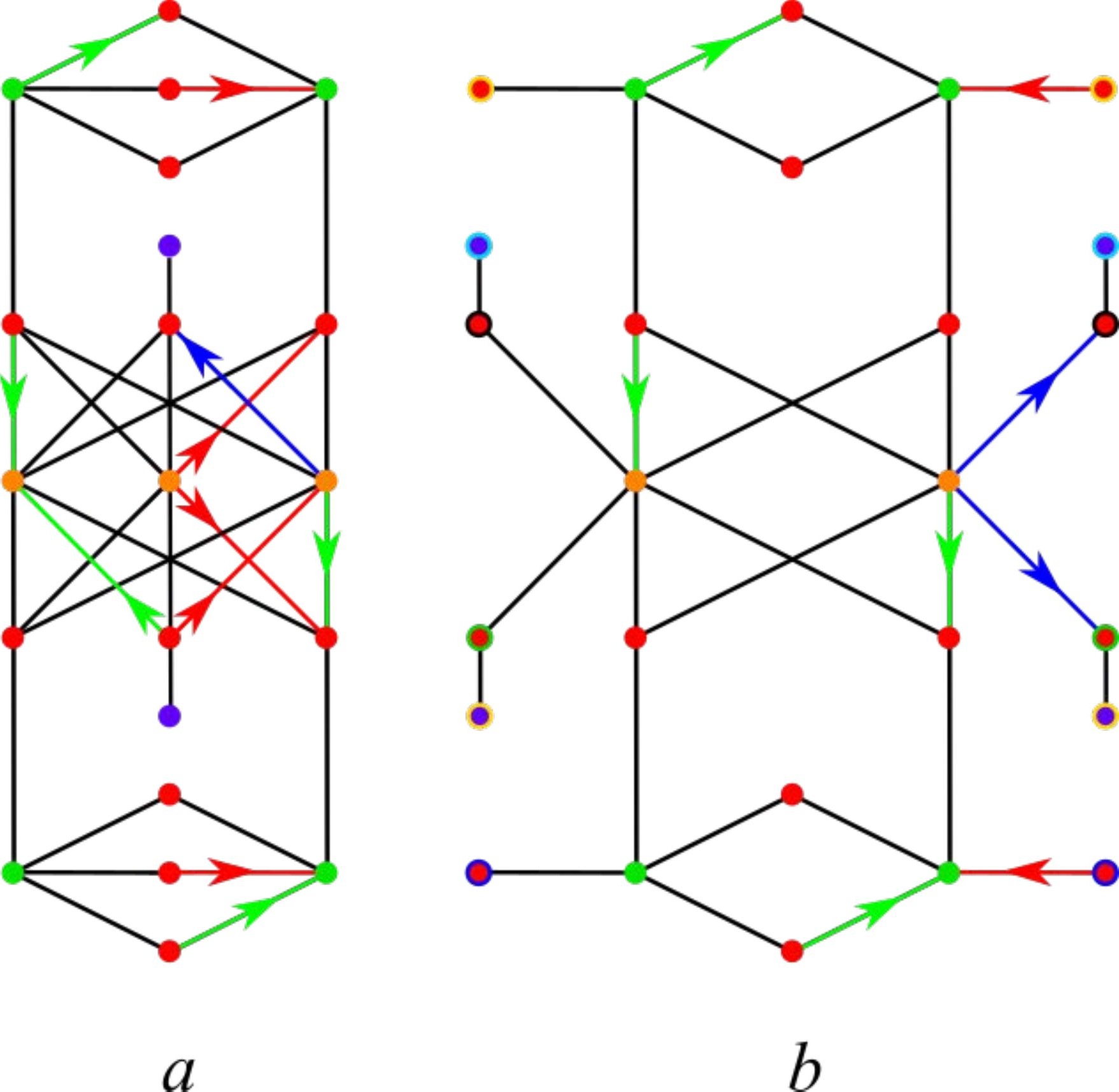




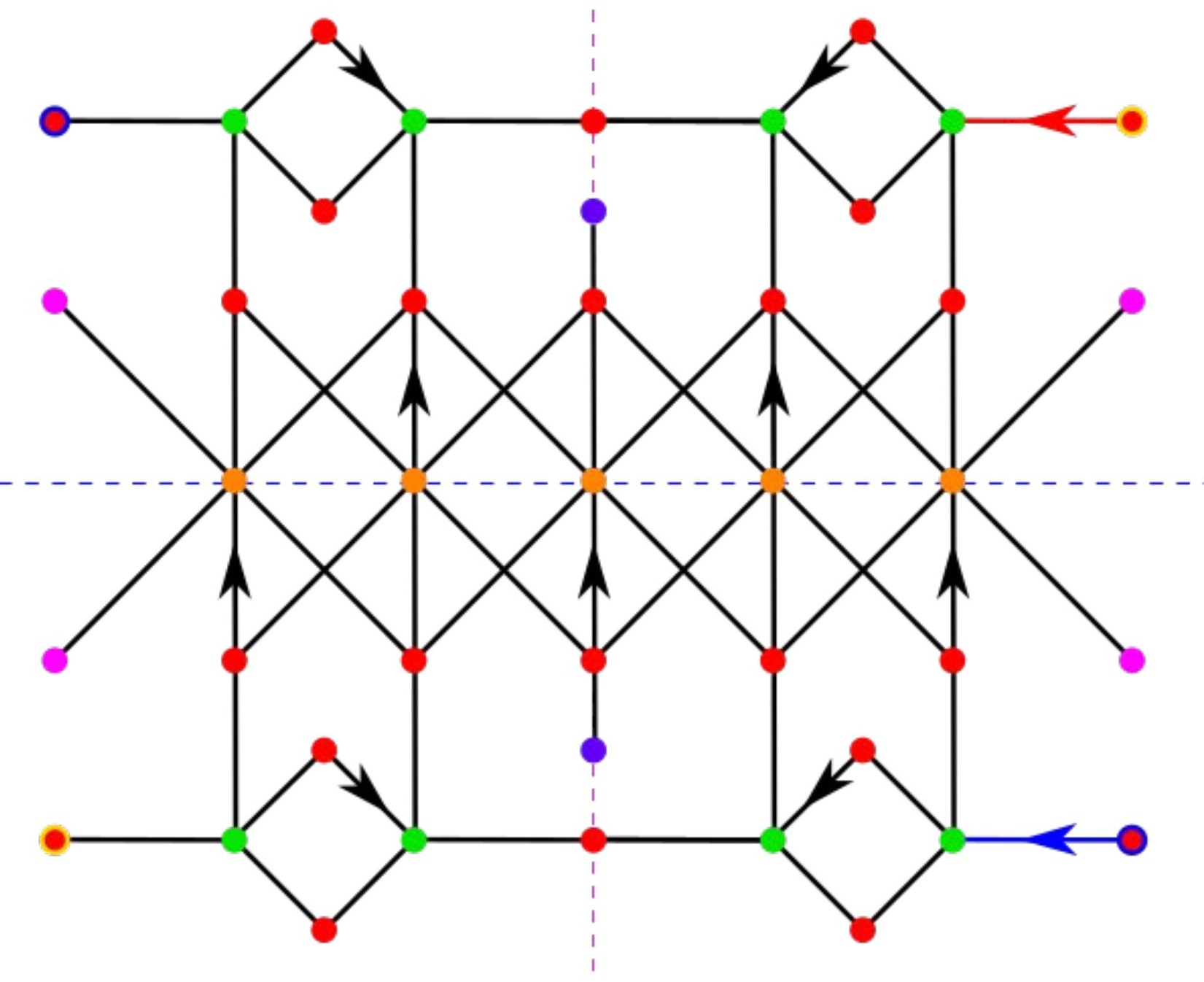




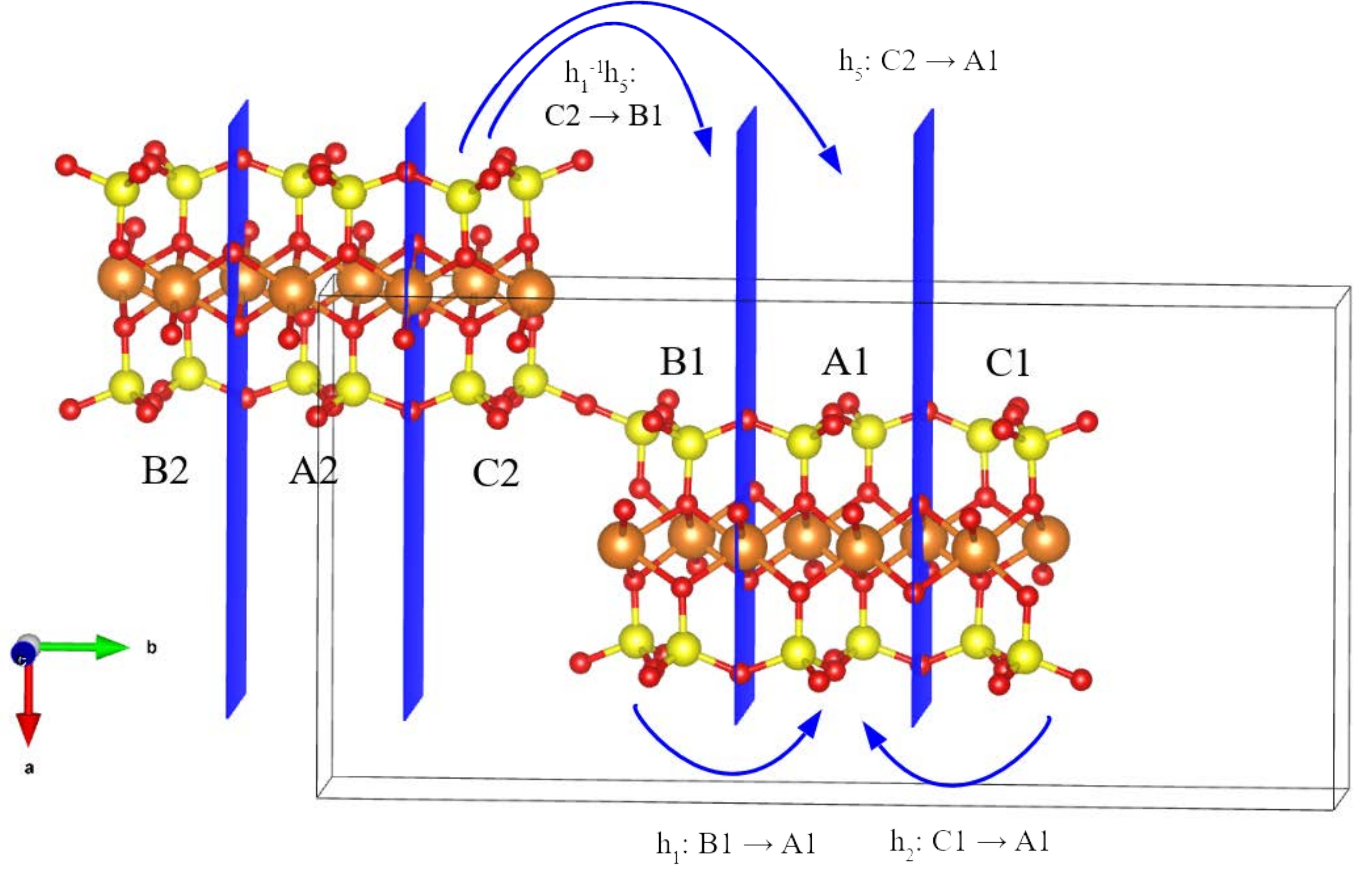




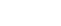

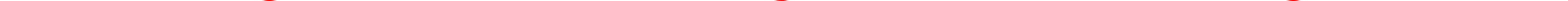




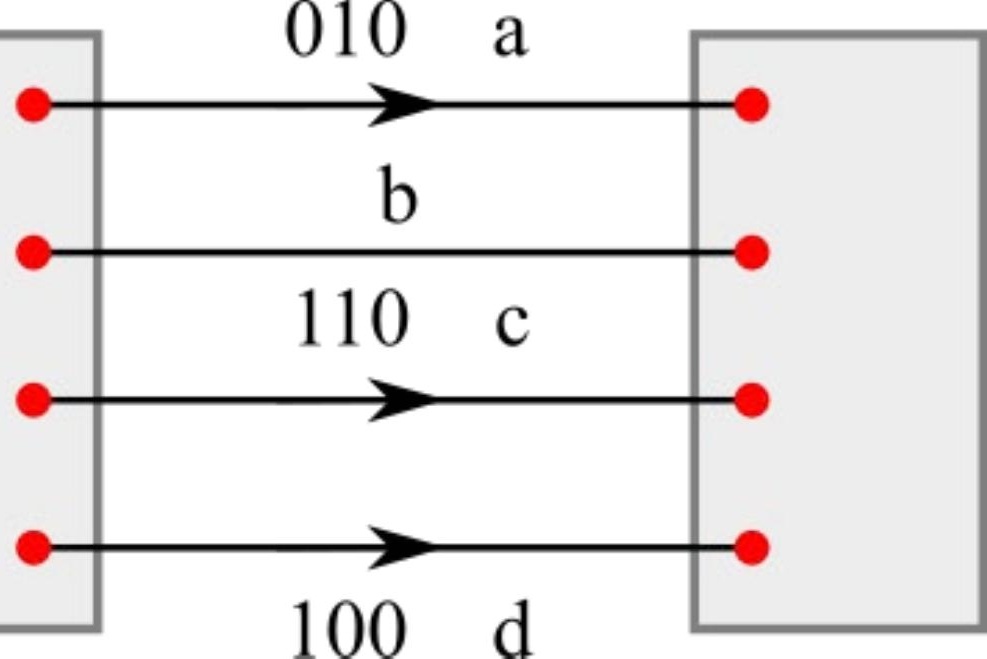




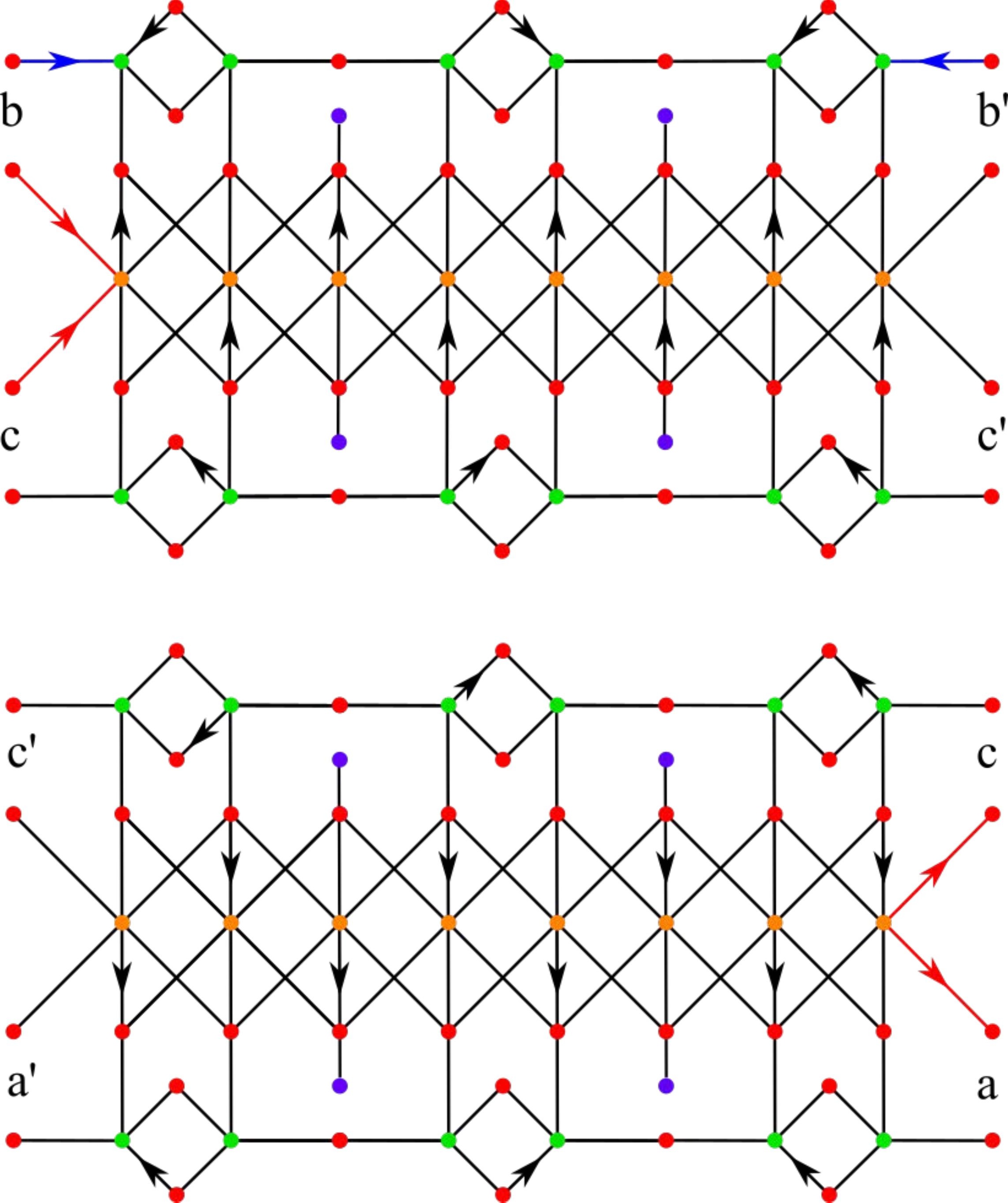



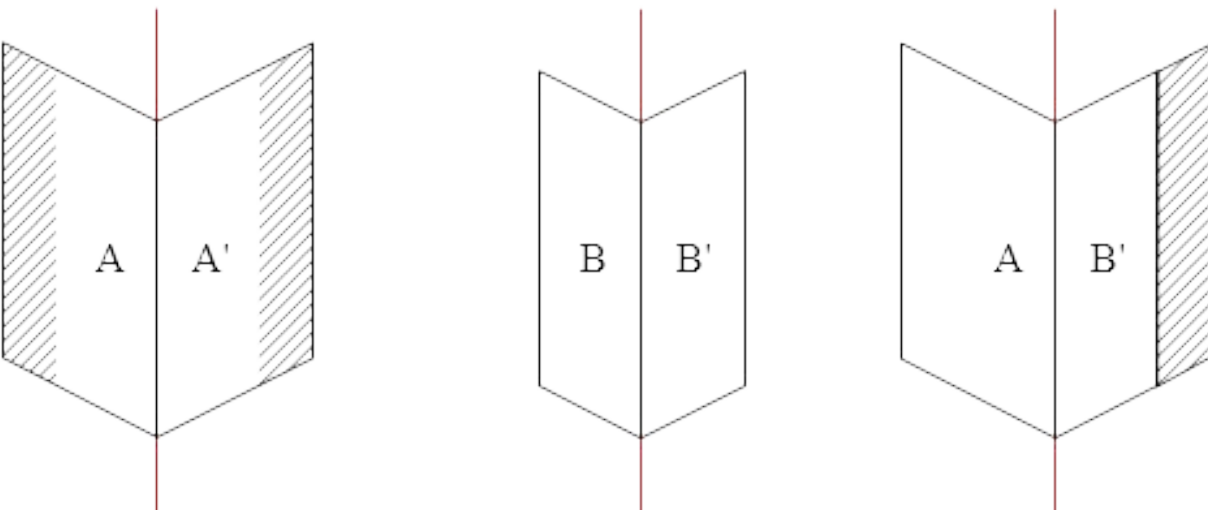
